\title{
Criminal Deterrence when There Are Offsetting Risks: Traffic Cameras, Vehicular Accidents, and Public Safety
}

\author{
By Justin Gallagher and Paul J. Fisher*
}

\begin{abstract}
Numerous cities have enacted electronic monitoring programs at traffic intersections in an effort to reduce the high number of vehicle accidents. The rationale is that the higher expected fines for running a red light will induce drivers to stop and lead to fewer cross-road collisions. However, the cameras also incentivize drivers to accept a greater accident risk from stopping. We evaluate the termination of a monitoring program via a voter referendum using 12 years of geocoded police accident data. We find that the cameras changed the composition of accidents but no evidence of a reduction in total accidents or injuries. (JEL D72, K42, R41)
\end{abstract}

T he automobile is a killer. In the United States, 36,675 people died in traffic accidents in 2014. The year before, 2.3 million people were injured in traffic accidents (Economist 2015). In urban areas, by far the most likely location for an accident is at a traffic intersection. Figure 1 shows annual accident rates for the city of Houston from 2003-2014 by 100-foot intervals from an intersection. Roughly 3 times as many accidents happen within 200 feet of an intersection than at any other distance 1

Over 438 communities in 23 states, including 36 of the 50 most populous US cities, have employed electronic monitoring programs in order to enforce traffic laws at intersections and reduce the number of accidents (Insurance Institute for Highway Safety (IIHS) 2016). Red-light camera programs specifically target drivers that run red lights. The assumption is that by incentivizing fewer drivers to run red lights via a dramatically higher probability of being caught, the total number of accidents will decline.

\footnotetext{
* Gallagher: Department of Agricultural Economics and Economics, Montana State University, P.O. Box 172920, Bozeman, MT 59717 (email: justin.gallagher1@montana.edu); Fisher: Department of Economics, University of Arizona, 1130 East Helen Street, Tucson, AZ 85721 (email: pauljfisher@email.arizona.edu). Matthew Notowidigo was coeditor for this article. The authors would like to thank seminar participants at Case Western Reserve University, Claremont Graduate University, Montana State University, UC Boulder, UC Irvine, and the University of Houston. A special thanks to Benjamin Hansen, Janet Kohlhase, Justin McCrary, and Robert Stein for feedback on the project, to Ann Holstein for expert GIS assistance, and to Michele L.S. Krantz for legal assistance regarding a Public Information Act Request. Jacqueline Blair, Simin Gao, Emily Luo, Ben Marks, Sarah Mattson, Kyle Musser, and Aaron Weisberg provided outstanding research assistance.

${ }^{\dagger}$ Go to https://doi.org/10.1257/pol.20170674 to visit the article page for additional materials and author disclosure statement(s) or to comment in the online discussion forum.

${ }^{1}$ The actual difference is likely much greater, as the figure does not control for the fact that many of the accidents outside of 200 feet of the reference intersection may be within 200 feet of another intersection.
} 


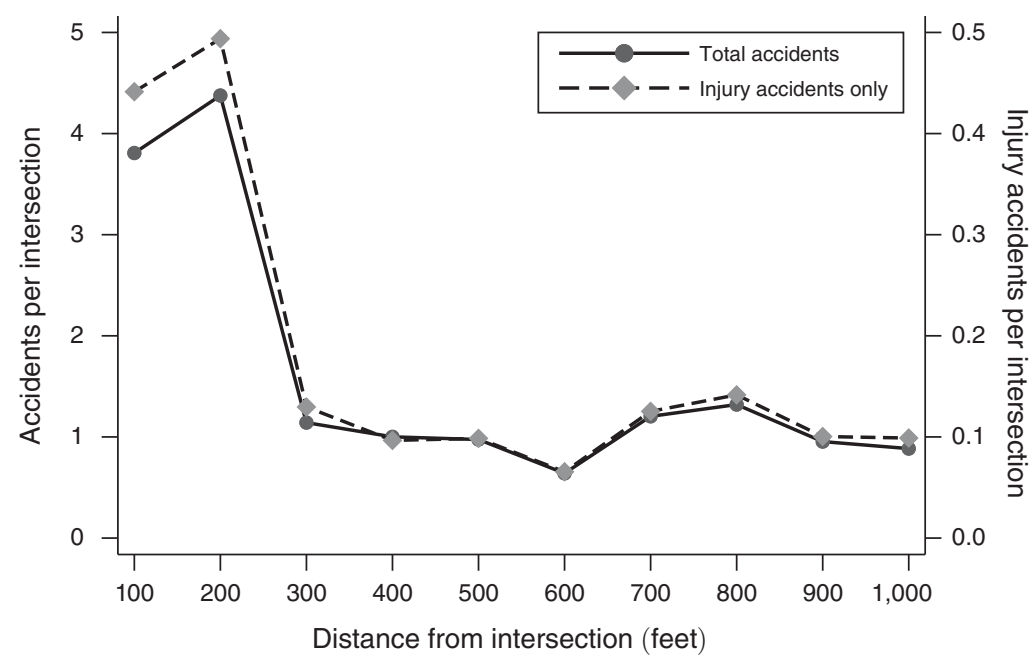

Figure 1. Average Yearly Accidents and Injury Accidents by Distance from an Urban Intersection

Notes: The figure plots average yearly total accidents and injury accidents by distance from a Houston intersection in 100-foot bins within 50 feet of a road for the years 2003-2014. The data include all accidents classified as "in or related" to the intersection by the police who recorded the accident. An "injury accident" includes one or more nonincapacitating injury, incapacitating injury, or death. The figure does not control for the fact that many of the accidents that are farther away from the reference intersection may be less than 200 feet from another intersection.

Source: Texas Department of Transportation

As a rule, law enforcement officials favor red-light camera programs and testify to their effectiveness. For example, the executive director of the Governors Highway Safety Association (GHSA) recently endorsed "the use of automated traffic enforcement technology, including red-light cameras, to improve safety for all road users. $[\ldots]$ It is mind-boggling that these proven safety tools are being removed despite numerous research studies validating their safety benefit" (GHSA 2016). ${ }^{2}$

Red-light camera programs (hereafter "camera programs") are distinct from other crime-reduction methods, for crime prevention is not an end in itself but serves as a mechanism to accomplish a broader policy goal. There is clear evidence that installing a camera reduces the number of vehicles running a red light. Still, the predicted relationship between the number of vehicles running red lights and the total number of accidents remains ambiguous.

A simple economic model shows that electronic monitoring via a red-light camera has contradictory effects in terms of traffic safety. First, some drivers who would have otherwise continued to proceed through the intersection when the light is yellow or red will now attempt to stop. The number of accidents caused by vehicles not stopping at a red light (i.e., angle accidents) will likely decrease. Second, the

\footnotetext{
${ }^{2}$ According to their website, the "GHSA provides leadership and representation for the states and territories to improve traffic safety, influence national policy, enhance program management and promote best practices" (http:// www.ghsa.org/resources/state-highway-safety-group-supports-red-light-cameras).
} 
number of accidents from stopping at a red light (i.e., rear-end accidents) is likely to increase. The reason is that driver awareness of the cameras will lead some drivers to attempt to stop and accept a higher accident risk from stopping at the intersection in order to avoid the expected fine from continuing through the intersection. Thus, the overall effect of the electronic monitoring on vehicle accidents and injuries depends on the net composition of the two effects. Overall driver safety could increase or decrease.

The main challenge in evaluating the effectiveness of camera programs is accounting for the endogenous start times and locations of the cameras. This challenge is an example of the now well-known problem that undermined many early tests of Becker's deterrence hypothesis regarding the probability of being caught and the reduction of crime (Becker 1968). ${ }^{3}$ For example, early empirical studies that tested whether an increase in policing intensity reduced crime often failed to detect any effect (e.g., Levitt and Miles 2006 and Chalfin and McCrary 2017 provide reviews). The change in the likelihood of being caught is often endogenous to the level of crime, which leads to a bias of finding no correlation (e.g., Levitt 1997).

In the context of a camera program, the endogeneity problem likely leads to overestimates of the program's effectiveness. Intersections chosen for cameras are not selected randomly. Intersections assigned cameras are often more dangerous (e.g., poor traffic flow, high traffic volume) than other intersections. Moreover, intersections with unusually high accident levels in the year just prior to the start of the program may be more likely to receive cameras. These same intersections are, in turn, regardless of intervention, more likely to revert to lower accident levels (mean reversion). We avoid concerns about the endogenous selection of intersections by examining the impact of the exogenous removal of cameras via a voter referendum.

We analyze whether electronic monitoring via red-light cameras is effective at reducing accidents and improving public safety in Houston, Texas. We chose Houston as the empirical setting of our study because it is a large US city that had a large camera program unexpectedly shut down due to a voter referendum. Houston established a camera program in 2006 that grew to include 66 intersections. Houston residents narrowly passed a voter referendum in November 2010 that banned the cameras. Both the Houston police department and the mayor's office opposed the ban (e.g., Oaklander 2011). After the referendum, the city immediately shut off the cameras.

We estimate a difference-in-difference model using Poisson regression and the complete police record of geocoded accident data for a 12-year period (2003-2014). We estimate models that separately examine the effect of the camera program on four types of accidents: angle, non-angle, total, and injury accidents. Angle accidents comprise about a third of the total number of accidents at a typical intersection and are the primary target of the program (Retting and Kyrychenko 2002). If electronic monitoring in Houston is successful at improving traffic safety, then we expect that the removal of the cameras would lead to an increase in the

\footnotetext{
${ }^{3}$ Interestingly, traffic crimes, while not a common setting to study Becker's deterrence predictions, are a specific crime highlighted in Becker $(1968,2)$.
} 
number of total accidents and injury accidents at camera intersections, relative to control intersections not subject to the referendum.

The estimates for angle and non-angle accidents support the predictions of the economic model. Our preferred econometric model uses a within-Houston control group of intersections without cameras. We select the Houston control intersections by estimating the propensity to have a Houston camera using a logit model that includes pre-referendum accident-related characteristics that have been cited as important criteria in selecting camera intersections (Stein, Levine, and Lomax 2006; City of Chicago 2015; Dallas Police Department 2016). We estimated that angle accidents increased by 26 percent and all other types of accidents decreased by 19 percent once the cameras are removed. We can statistically reject that the coefficients are equal.

Overall, we find no evidence that cameras reduce the total number of accidents or injuries. We estimate a statistically insignificant reduction in total accidents ( -4 percent) and a negative, statistically insignificant change in the number of injury accidents after the camera program ends. We adapt the model of Chalfin and McCrary (2018) to interpret how electronic monitoring at traffic intersections affects social welfare. Using our estimates for changes in the types of injuries incurred in traffic accidents (fatalities, incapacitating, nonincapacitating, possible, no injury), the model suggests that the camera program led to a decrease in social welfare.

One potential identification concern for our econometric model is that cameras could affect driving behavior at noncamera intersections in the city (e.g., Shin and Washington 2007; Høye 2013; Wong 2014). For example, drivers may alter their routes to avoid camera intersections. If this were the case, traffic volume at the noncamera intersections would increase and thereby bias our model estimates toward finding larger beneficial effects of the program. We test for a change in average daily traffic measured at the intersections in our main sample and find suggestive evidence of a small increase in traffic at noncamera intersections. We also consider a second, out-of-city control group, the camera intersections of Dallas, which was not subject to the referendum. Model estimates using the Dallas control group confirm our main results.

The camera program as a policing tool is a key topic in transportation and safety journals (e.g., Erke 2009; Høye 2013; and Goldenbeld, Daniels, and Schermers 2019 provide reviews), but the economics literature on this topic is scant at best (Chen and Warburton 2006 and Wong 2014 are exceptions). Most studies either compare city-level accident data between cities with and without cameras (e.g., Hu and Cicchino 2017) or focus on a very small number of intersections. Nearly all of the intersection-level studies use "empirical Bayes" (Hauer 1997) as an estimation approach. The idea of the empirical Bayes model is that traffic model estimates from a group of out-of-sample intersections can be used to correct for mean reversion at camera intersections. The key modeling step is to linearly combine the actual number of accidents at camera intersections with the predicted number of accidents from the out-of-sample intersections. We show that the empirical Bayes estimates still suffer from mean reversion and will overestimate the beneficial safety effect of camera programs. 
In contrast to the existing literature, we use the exogenous shutoff of the traffic cameras as a natural experiment. We conclude that the traffic safety benefit of camera programs is much smaller than the consensus view in the existing transportation and engineering literatures. In the case of Houston, our preferred estimates suggest that the change in social welfare from implementing the camera program was negative. More generally, our study highlights the challenge of using policy tools to deter crime in situations where potential offenders face multiple offsetting risks.

\section{Driver Behavioral Model}

Becker's model of crime predicts that the fraction of drivers breaking the law and running a red light will decrease when the expected penalty for running a red light increases (Becker 1968). Driver $i$ approaches intersection $j$ at time $t$ as the signal light turns from green to yellow. The driver decides whether to attempt to stop or to continue and proceed through the intersection. A driver will choose (potentially) to run a red light if the expected utility from continuing exceeds the expected utility of stopping. Equations (1) and (2) model the utility from continuing to drive and attempting to stop, respectively:

$$
\begin{aligned}
C_{i j t} & =u\left(T_{i j t}, F_{i j t}, A_{i j t}, \xi_{i j t} ; D_{i j t}\right), \\
S_{i j t} & =u\left(A_{i j t}, \psi_{i j t} ; D_{i j t}\right) .
\end{aligned}
$$

The benefit of continuing is assumed to largely be due to $T_{i j t}$, the travel time savings of not having to wait at a red light, which can vary by driver (e.g., hourly salary), intersection (e.g., length of red-light phase of traffic signal), and time of day (e.g., whether the driver is commuting to work). The anticipated fine, $F_{i j t}$, depends upon the likelihood that the driver's vehicle passes through the intersection before the light turns from yellow to red, the probability of receiving a ticket if the vehicle is in the intersection after the light turns red, and the size of the fine. The variable $A_{i j t}$ is the cost of an accident and enters both utility functions; $A_{i j t}$ depends on the probability of being in an accident and the monetized vehicle damage and injury costs conditional on being in an accident. Finally, $\xi_{i j t}$ and $\psi_{i j t}$ represent all other factors that would affect a driver's utility of continuing and stopping (e.g., willingness to break the law). All of the factors discussed above are conditional on the distance, $D_{i j t}$, that the driver is from the intersection when the light turns yellow.

\section{A. Number of Vehicles Running Red Lights}

A camera decreases the utility of continuing through the intersection after the light turns yellow by increasing $F_{i j t}$ via a dramatic increase in the probability of receiving a ticket. The probability of receiving a ticket for running a red light at an intersection without a camera remains low, for it requires a police officer to witness the infraction. The probability of receiving a ticket when there is a camera at the intersection is close to 100 percent. 
One general challenge in evaluating how potential offenders respond to a deterrent is that the perception of being caught might not reflect the probability of being caught (e.g., Waldo and Chiricos 1972, Apel 2013, Chalfin and McCrary 2017). An advantage of studying the deterrence effect in the context of camera programs is that we can confirm a change of perception among drivers after a camera is installed.

In the first year after the end of electronic monitoring, the number of red-light-running tickets issued citywide $(17,282)$ barely exceeded the number of tickets issued at a single intersection $(17,055)$ in the final fiscal year of Houston's camera program. Figure 2 panel A plots the average number of tickets per fiscal year for Houston camera intersections. The number of tickets issued dropped by 99.9 percent in the year after electronic monitoring ended.

Previous studies use direct observations of driver behavior to confirm that the number of vehicles running a red light at an intersection declines after a camera is installed (e.g., Retting, Ferguson, and Hakkert 2003; Martinez and Porter 2006; Erke 2009; Porter, Johnson, and Bland 2013). ${ }^{4}$ The total number of tickets issued at camera intersections also supports the prediction of a decrease in red-light running after a camera is installed. In general, the number of tickets issued for running a red light at a camera intersection peaks immediately after the installation of the camera and then begins to decline as drivers learn about the camera and adjust their behavior. Figure 2 panel B plots the average yearly number of citations per intersection by year of operation for Dallas camera intersections. On average, in the first year of a camera-monitored intersection, more than 6,000 citations are issued. In the second year of operation, there are about 66 percent fewer tickets issued. ${ }^{5}$

\section{B. Number of Total Accidents}

The policy objective of electronic monitoring is to decrease the number of total accidents and related passenger injuries. While there is clear evidence that installing a camera reduces the number of vehicles running a red light, the predicted relationship between the number of vehicles running red lights and the total number of accidents is ambiguous.

Right-angle crashes between two vehicles are likely to decrease under electronic monitoring. Some drivers who typically ran a red light before a camera program will choose to stop at the intersection and, in turn, fewer vehicles will be in the intersection when the cross-road light turns green. In fact, the explicit goal of most camera programs is to reduce the number of total accidents through a reduction in angle accidents (Erke 2009).

\footnotetext{
${ }^{4}$ Martinez and Porter (2006) concludes that the incidence of red-light running fell by 67 percent during the eight months immediately after the camera installation. In a follow-up study, Porter, Johnson, and Bland (2013) estimates that the incidence of red-light running begins to return to the precamera levels immediately after the removal of the cameras and that a year after removal the rate of running a red light is similar to before the camera was installed.

${ }^{5}$ We are unable to produce a similar figure for Houston because we are only able to access intersection-level citation reports for two years of Houston's program (2008-2009 and 2009-2010).
} 
Panel A. Citations at Houston camera intersections

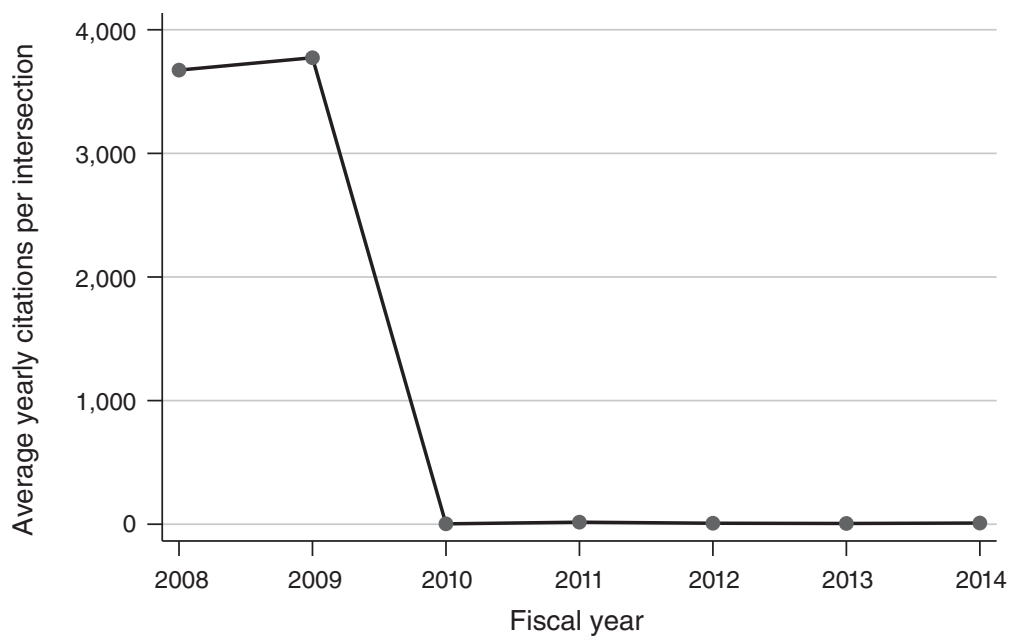

Panel B. Camera citations at Dallas intersections

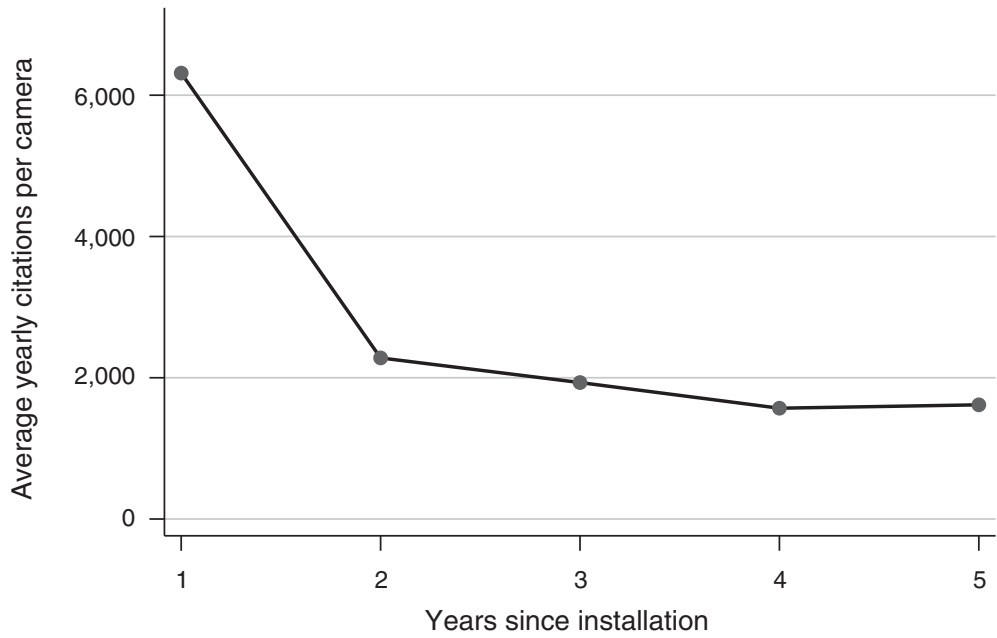

Figure 2. Red-Light Citation Rates

Notes: Panel A plots the number of annual (fiscal year) red-light-running citations at the 66 Houston camera intersections from 2008-2014. 2008 and 2009 include both camera-initiated citations and citations from law enforcement officials. The points for 2010-2014 are for after the camera program ended and include only law enforcement citations. Missing from the figure are the camera citations for the first four months of fiscal year 2010 (July-October). To our knowledge, these data were never made public. Panel B plots the number of annual camera citations by intersection and years since installation for Dallas camera intersections. The figure reports citation data from 2 cameras for year 1, 37 for years 2 to 4, and 29 for year 5. Fiscal year reports with camera citation information are not available (or not usable) for all years of the Dallas program. See the online Appendix for details.

Source: City of Houston, Texas Department of Transportation 
At the same time, electronic monitoring is likely to increase other types of accidents. ${ }^{6}$ Here we consider four reasons. First, drivers will now accept a higher accident-related cost from attempting to stop. The marginal driver will choose to stop and accept the greater risk of a non-angle accident, along with the associated costs, provided that these costs are less than the expected fine. Second, a lengthy transportation and engineering literature documents the role that changes in speed (rather than speed levels) have on accident rates (e.g., Gazis, Herman, and Maradudin 1960; Hurwitz, Knodler, and Nyquist 2011).7 Even if the driver changing speed can do so safely, other drivers may not be able to react in time to avoid an accident. Notably, neither of these first two reasons depend on imperfect information or calculation errors by the driver.

Third, if there is uncertainty over the stopping distance (e.g., poor weather conditions, driver unfamiliarity with the intersection), then the increase in the fine under a camera program may incentivize drivers to attempt to stop when it would be safer to continue. Fourth, drivers may simply miscalculate. The decision to stop or continue is a split-second decision. For example, knowledge of the cameras (perhaps cued by the posted signs) could lead some drivers' first impulse to be to stop even when it would be safer to continue through the intersection (Kapoor and Magesan 2014). 8

The overall effect of a camera program on the total number of accidents will depend on the relative magnitudes of those accident types that are likely to decrease and those that are likely to increase. One advantage of the accident data discussed in Section IIIB is that all accidents are categorized into a detailed list of accident types. We are able to estimate the effect of a camera program on total accidents as well as the effect on specific accident types.

\section{Previous Literature}

Online Appendix Table 1 lists information for 21 recent camera studies that were published in the last 10 years. This list is largely based off of the studies included in the meta-analyses by Høye (2013) and Goldenbeld, Daniels, and Schermers (2019). All of the studies in the table estimate the causal effect of the cameras from the camera installation, while three also estimate the causal effect when cameras are removed (Pulugurtha and Otturu 2014, Hu and Cicchino 2017, Ko et al. 2017). All but 1 of the 16 peer-reviewed studies are published in engineering or

\footnotetext{
${ }^{6}$ In our main analysis, we divide accidents into two groups (angle and non-angle). There are several reasons why we prefer this (somewhat coarse) division of accidents. First, camera policies explicitly target angle accidents. Second, the driver behavioral model predicts that there will be an increase in "other" types of accidents but does not provide a prediction for exactly which types. We are not traffic engineers and do not feel that we have the expertise to tailor the prediction to a select subset of accident types. At the same time, we are also skeptical that the traffic engineering models are sufficiently reliable to do this.

${ }^{7}$ Gazis, Herman, and Maradudin (1960) models the distance required for a vehicle approaching a traffic intersection to safely decelerate and stop. Gazis, Herman, and Maradudin (1960) shows that there will always be a "dilemma zone" under the Federal Highway Administration guidelines, which recommend a yellow-light duration of three to six seconds (US Federal Highway Administration 2009). The dilemma zone is the area proximate to an intersection where a driver can neither safely stop nor pass through the intersection without accelerating before the light turns from yellow to red.

${ }^{8}$ Kapoor and Magesan (2014) shows that the introduction of pedestrian crosswalk countdown signals that are also visible to drivers have the unintended effect of increasing the number of vehicle accidents.
} 
transportation journals (Langland-Orban, Pracht, and Large 2014 is the exception). Most also examine how cameras affect accident subcategories and typically focus on right-angle and rear-end accidents. The online Appendix includes a detailed discussion of several prominent camera studies.

The general consensus of the current literature is that cameras are effective at reducing accidents and accident injuries. Goldenbeld, Daniels, and Schermers (2019) considers studies published since Høye (2013) and concludes that cameras reduce total accidents by 12 percent. Goldenbeld, Daniels, and Schermers (2019) only includes studies in the meta-analysis that are "methodologically sound" (p. 140). Fourteen of the 18 studies in Goldenbeld, Daniels, and Schermers (2019) use the empirical Bayes (EB) method. In our view, problems with the methodological approach of the current literature, and the EB model in particular, have led to the unfounded conclusion that cameras improve public safety.

The empirical Bayes model is the standard model used in intersection-level camera studies (e.g., Abbess, Jarrett, and Wright 1981; Hauer 1992; Hauer et al. 2002; Hauer 1986). It is widely claimed that the EB model corrects for mean reversion while also improving statistical precision..$^{9}$ Mean reversion is likely to occur as cameras are often placed at intersections that experienced high accident levels in the years immediately before the start of the program.

The empirical Bayes model has two significant drawbacks that together make it very unlikely to produce unbiased causal estimates. First, empirical Bayes is a "model-driven approach" that relies on estimating the precise "structural relation" between accidents and the road characteristics that cause accidents (Angrist and Pischke 2017, 1). The first step is to estimate the "safety performance function" (SPF) on an out-of-sample group of intersections. The estimated parameter values from the SPF are then applied to the camera intersections to obtain the predicted number of accidents. These accident predictions are susceptible to bias from model misspecification. In practice, the SPF often includes a small number of intersection characteristics such as average daily traffic, number of lanes, speed limit, lane width, and right-turn-on-red prohibition (e.g., Lord and Greedipally 2014; Mahmassani et al. 2017). Several recent papers use only average daily traffic to model the SPF (e.g., Ko, Geedipally, and Walden 2013; Pulugurtha and Otturu 2014; Ko et al. 2017).

The second major drawback is how the model corrects for mean reversion. The key methodological step is to take a weighted average of the predicted and actual number of accidents in the posttreatment period. This weighted average, which is supposed to correct for mean reversion, is then subtracted from the level of preprogram accidents at the same camera intersections to determine the camera policy treatment effect. The weighting formula is selected to minimize the variance of the empirical Bayes estimator (Hauer 1997). This typically leads to a very large

\footnotetext{
${ }^{9}$ The EB model has become largely associated with Ezra Hauer. Hauer et al. (2002) states: "The empirical Bayes (EB) method for the estimation of safety increases the precision of estimation and corrects for the regression-to-mean bias" (126). Persaud and Lyon (2007) states that "the empirical Bayes (EB) methodology has been applied for over 20 years [...] The appeal of the methodology is that it corrects for regression to the mean" (1). Høye (2013) states: "Since no obvious weaknesses in the application of the EB method were found, all of these studies can be assumed to be largely unaffected by [mean reversion]" (81).
} 
weight on the actual intersection accident data and, as a result, does little to correct for mean reversion. The model would only eliminate mean reversion (when it exists) if all of the weight is on the predicted number of accidents.

The online Appendix includes a lengthy discussion of the empirical Bayes model. In particular, we run a Monte Carlo simulation where we randomly generate accident data and evaluate a placebo camera program. The placebo cameras are assigned to intersections that randomly have a high number of accidents in the years before the program. The empirical Bayes model treatment estimates imply that the introduction of placebo cameras lead to a statistically significant reduction in total accidents. This is true regardless of how well the structural performance function models the true accident-generating process.

In summary, the EB model's failure to correct for mean reversion and the model's emphasis on statistical precision together can account for the large number of studies that conclude camera programs reduce intersection accidents. In contrast to the current literature, our empirical strategy follows a "design-based" econometric approach (Angrist and Pischke 2017) that does not rely on correctly modeling the entire accident-generating process.

\section{Background and Data Sources}

\section{A. Houston and Dallas Camera Programs}

All camera programs share several characteristics. A camera is installed in a location where it can take photos (or video) of vehicles as they pass through the intersection. The camera is positioned so that photos include the vehicle in the intersection and its license plate. Photos of all vehicles captured passing through the intersection are to be reviewed by city employees, a contractor, or both in order to verify that the light is red and the license plate is clearly visible. Tickets are then sent to the home address of the individual who registered the vehicle. The main characteristics on which camera programs differ include whether signage identifies a camera-enforced intersection, whether the cameras are permanent fixtures or mobile units, and whether the cameras also monitor vehicle speed and issue speeding tickets.

Houston first approved the installation of red-light cameras in 2004 and installed 20 cameras in 2006 and 46 in 2007 (Hassan 2006). Approximately 800,000\$75 tickets were issued from 2006 to 2010 for a total of about $\$ 44$ million collected (Olson 2010). The first 33 Dallas cameras were installed in 2007, along with 22 more between 2008-2011. The Dallas program also issued \$75 fines and in fiscal year 2008-2009 gave out 129,000 tickets. In Houston and Dallas, programs included posted signs advising drivers of the cameras and permanently placed cameras and issued tickets only for red-light infractions. The Dallas camera program remained in place throughout our panel.

In November 2010, Houston residents voted 53 percent to 47 percent in favor of a referendum to remove the cameras. The referendum was organized by citizens who opposed the camera program on the grounds that the cameras were mainly a revenue-raising policy. At the time of the referendum, a majority of members on the Houston City Council approved of the program, as did the Houston Police Department 
(Houston Chronicle 2010, Olson 2010, Oaklander 2011). After the voter referendum, Houston immediately shut off the cameras and began legal proceedings with the private subcontractor that administered the cameras (Jensen 2010). In July 2011, a judge ruled that Houston had breached its contract (which was set to run through 2014) and the cameras were briefly turned back on. One month later, the Houston City Council voted to repeal the original law that authorized the usage of the cameras (Garrett 2011). All lawsuits related to the removal of the cameras were settled by January 2012 (Houston Mayor's Office 2012).

Figure 3 shows that Houston residents were well aware of the referendum. The three panels display the counts of newspaper stories (panel A), broadcast news stories (panel B), and Google online search interest (panel C) in red-light cameras as compared to Houston's newly elected mayor. Annise Parker, Houston's first openly LGBT mayor, was elected in a runoff election 11 months before the referendum in December 2009. The top two panels plot the number of monthly news stories in the month of the referendum (month 0) and in each of the 24 months before and after the referendum. News stories include the phrases "red-light camera" or "Annise Parker." The bottom panel shows the Google trends measure of interest in the same two terms. A value of 100 indicates peak popularity, whereas a score of 50 means the term is half as popular. The spikes in the number of news stories and online searches related to red-light cameras at the time of the referendum are roughly comparable to those for Annise Parker at the time of her election. ${ }^{10}$

\section{B. Data Sources}

Intersection Information.-We use information on camera intersections from the annual (fiscal year) camera intersection reports of the Texas Department of Transportation (TxDOT) (2009-2016). The earliest available reports are from 2009. These reports are compiled and published by the state of Texas using information submitted by municipalities. Each municipality with a camera program is required to submit annual information on each camera, including the date of installation, intersection speed limits, total tickets issued, and an estimate for the average daily traffic (ADT). Unfortunately, the Houston report for 2010-2011, which covers the last four months of the camera program, was not published. Another data limitation is that ADT is measured only once at most of the camera intersections and not updated annually.

We also collect ADT information from two other sources that provide traffic counts in Houston and Dallas at numerous street locations (North Central Texas Council of Governments 2016 and City of Houston 2017). The use of street-based (rather than intersection-based) ADT information allows us to have a consistent ADT measure for camera and noncamera intersections in each city. Intersections are assigned ADT values using GIS software by summing the ADT values for all roads at the intersection. The online Appendix includes details regarding the ADT calculation.

Finally, we collect information on a number of structural intersection characteristics, including whether one or more of the streets at the intersection has a

\footnotetext{
${ }^{10}$ The source of the newspaper stories is the Houston Chronicle. The broadcast news stories are from closed captioning data provided by Metro Monitor and cover Houston's ABC, CBS, FOX, and NBC affiliates.
} 
Panel A

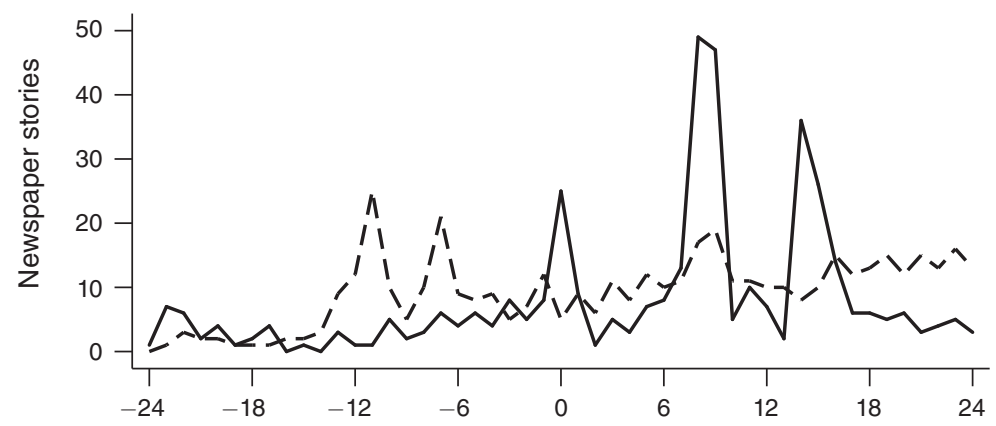

Panel B

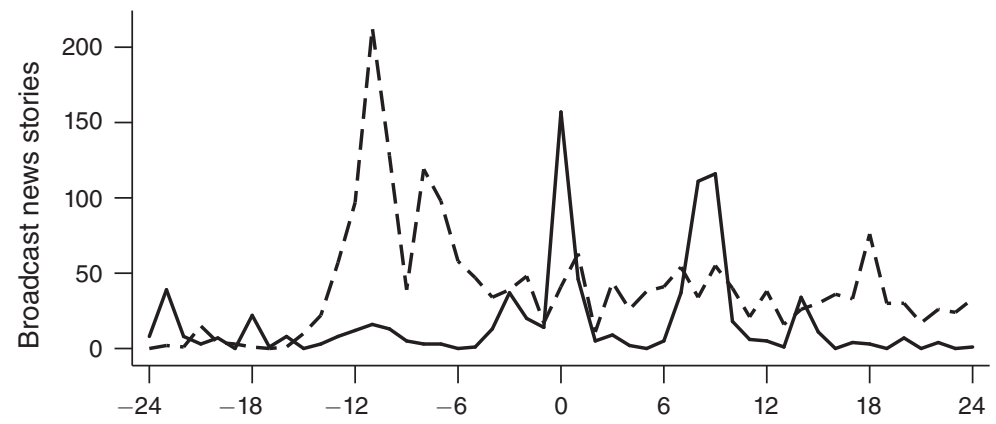

Panel C

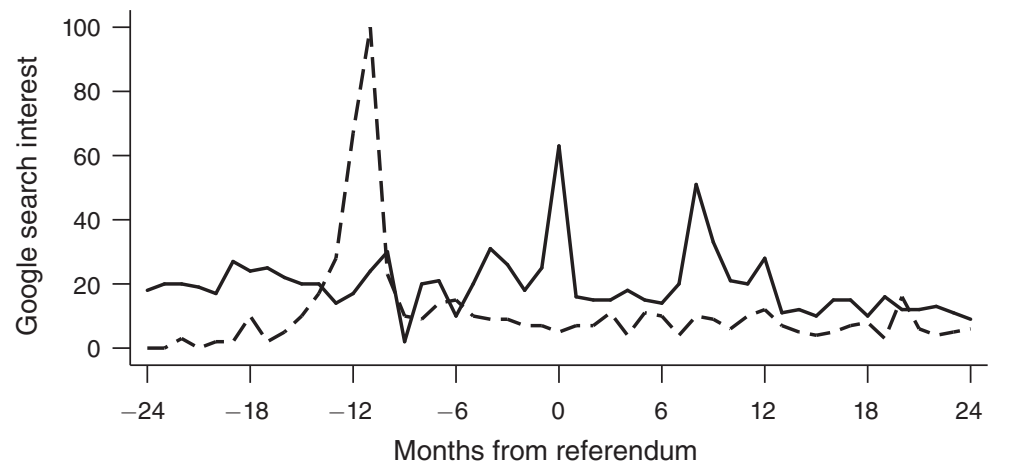

Red light camera - - - - Annise Parker

Figure 3. Camera Referendum Media News Story Frequency and Google Search Interest

Notes: The three panels display the counts of newspaper stories (panel A), broadcast news stories (panel B), and Google online search interest (panel C) in red-light cameras as compared to Houston's newly elected mayor. Annise Parker, Houston's first openly LGBT mayor, was elected in a run-off election 11 months before the referendum in December 2009. The top two panels plot the number of monthly news stories in the month of the referendum (month 0) and in each of the 24 months before/after the referendum. News stories include the phrases "red-light camera" or "Annise Parker." The bottom panel shows the Google trends measure of interest in the same two terms. A value of 100 indicates peak popularity, whereas a score of 50 means the term is half as popular.

Sources: Houston Chronicle, Google trends, Metro Monitor 
median separating traffic, the speed limit, the number of lanes, and whether the intersection includes a frontage road. A frontage road runs parallel to a highway and often provides an access point to the highway. ${ }^{11}$

Vehicle Accidents.-The 2003-2014 accident data from the TxDOT Crash Records Information System (CRIS) include all reported motor vehicle traffic accidents in the state (University of Texas at Austin Center for Transportation Research 2003-2009, TxDOT 2009-2016). ${ }^{12}$ The accident data retained in CRIS are from crash reports filled out by law enforcement personnel. CRIS includes information on the location of each accident (latitude and longitude coordinates), type of accident (e.g., right angle), driver behavioral information (e.g., drugs or alcohol detected, whether the driver ran a red light), accident injury information, and the weather at the time of the accident. The 2010-2014 CRIS data include the month and year of the accident, while the earlier data include only the year.

We use GIS software to identify accidents that occur within 200 feet of an intersection and within 50 feet of a road for all Houston intersections and all Dallas camera intersections. Recall that Figure 1 indicates much higher accident rates within 200 feet of an intersection. We further restrict our sample to those accidents where law enforcement personnel determined that the accident was "in or related to" an intersection, rather than an adjacent parking lot for example. We define these accidents as "intersection accidents." We only include intersection accidents in our main estimation panels.

Table 1 shows average yearly accident statistics for Houston for the three years before the start of the camera program (2003-2005). Panel A displays statistics for all accidents, while panel B only displays statistics for intersection accidents in our main Houston panel. We calculate each statistic separately for all accidents, angle accidents, and non-angle accidents. We define "angle accident" as an accident type listed in CRIS that includes the word "angle." There are 45 accident types listed in CRIS, of which 10 include the word "angle." The online Appendix includes a complete list of accident types. ${ }^{13}$

Of the 77,000 accidents per year in Houston, 34 percent are in or related to an intersection. The proportion of angle accidents is larger among intersection accidents than for all Houston accidents (39 percent versus 21 percent). On average, there are 231 fatalities per year. Overall, the likelihood of being killed in an intersection accident is higher for non-angle accidents than for angle accidents conditional on each accident type.

The CRIS database includes six accident injury designations: fatality, incapacitating, nonincapacitating, possible, unknown, and none. The categories are mutually exclusive. If multiple individuals are injured in an accident, then the accident

\footnotetext{
${ }^{11}$ Intersection characteristics were collected using Google Maps (https://www.google.com/maps), Google Mapmaker, and Waze (https://www.waze.com/) from June-July 2016. The dates of the images used to collect the data roughly match the end of our panel period.

${ }^{12}$ The 2010-2014 data were downloaded via the TxDOT online database. CRIS data prior to 2010 are no longer retained by TxDOT. CRIS data for the years 2003-2009 were obtained via an open records request under the Texas Public Information Act from the University of Texas at Austin Center for Transportation Research.

${ }^{13}$ Each of the ten angle accident types include a more precise description. The most common angle accident is "Angle: Both Going Straight," which involves 78 percent of angle accidents.
} 
Table 1-Accident and InJury Descriptive Statistics

\begin{tabular}{|c|c|c|c|}
\hline $\begin{array}{l}\text { Accident type: } \\
\text { Average yearly statistics }\end{array}$ & $\begin{array}{l}\text { All } \\
(1)\end{array}$ & $\begin{array}{l}\text { Angle } \\
(2)\end{array}$ & $\begin{array}{c}\text { Non-angle } \\
\text { (3) }\end{array}$ \\
\hline \multicolumn{4}{|l|}{ Panel A. All Houston accidents } \\
\hline \multicolumn{4}{|l|}{ Total accidents } \\
\hline Number of accidents & 77,552 & 16,233 & 61,319 \\
\hline Fraction of accidents by type & 1.00 & 0.21 & 0.79 \\
\hline Number of fatalities & 231.00 & 35.67 & 195.33 \\
\hline Fraction "in or related to" intersection & 0.34 & 0.77 & 0.23 \\
\hline \multicolumn{4}{|l|}{ Injury accidents, fraction by severity } \\
\hline Fatality & 0.003 & 0.002 & 0.003 \\
\hline Incapacitating injury & 0.016 & 0.020 & 0.015 \\
\hline Nonincapacitating injury & 0.067 & 0.090 & 0.061 \\
\hline Possible injury & 0.265 & 0.351 & 0.242 \\
\hline Unknown injury & 0.290 & 0.141 & 0.329 \\
\hline No injury classification & 0.359 & 0.397 & 0.349 \\
\hline \multicolumn{4}{|c|}{ Panel B. Houston sample intersection accidents } \\
\hline \multicolumn{4}{|c|}{ Total accidents } \\
\hline Number of accidents & 1,598 & 625 & 973 \\
\hline Fraction of accidents by type & 1.00 & 0.39 & 0.61 \\
\hline Number of fatalities & 2.00 & 2.00 & 0.00 \\
\hline \multicolumn{4}{|l|}{ Injury accidents, fraction by severity } \\
\hline Fatality & 0.001 & 0.002 & 0.000 \\
\hline Incapacitating injury & 0.020 & 0.029 & 0.015 \\
\hline Nonincapacitating injury & 0.087 & 0.121 & 0.065 \\
\hline Possible injury & 0.317 & 0.390 & 0.270 \\
\hline Unknown injury & 0.207 & 0.126 & 0.259 \\
\hline No injury classification & 0.368 & 0.332 & 0.391 \\
\hline
\end{tabular}

Notes: The table shows average yearly accidents in Houston for the three years before the camera program (2003-2005). Panel A displays statistics for all accidents, while panel B displays statistics only for intersection accidents in our main Houston panel. There are six accident injury designations: fatality, incapacitating, nonincapacitating, possible, unknown, and none. The categories are mutually exclusive. If there are multiple individuals injured in an accident, the accident designation corresponds to the most severe injury.

Source: Texas Department of Transportation

designation corresponds to the most severe injury. The database includes pedestrians injured by a vehicle accident.

The probability of incurring a nonfatal injury from an intersection accident is greater for individuals involved in angle accidents than in non-angle accidents. There are approximately twice as many incapacitating angle accidents than non-angle accidents at an intersection (0.029 versus 0.015$)$. Moreover, the fraction of nonincapacitating injury accidents among angle accidents is 0.121 , whereas for non-angle accidents it is 0.065 . Given that intersection angle accidents are more dangerous than intersection non-angle accidents, a change in the composition of the types of accidents could have important welfare implications even if there is no effect on the total number of accidents.

Figure 4 plots the average total number of vehicle accidents per intersection by year from 2003-2014. Panel A plots accident levels for the 66 Houston camera intersections in our study as well as Houston intersections with ADT data and at least 1 accident during our panel that did not have a camera. ${ }^{14}$ Panel B plots

\footnotetext{
${ }^{14}$ We combine the 20 cameras installed in 2006 and the 46 installed in 2007 into 1 plot. Separate plots for the 2006 and 2007 cameras are very similar.
} 
Panel A. Houston

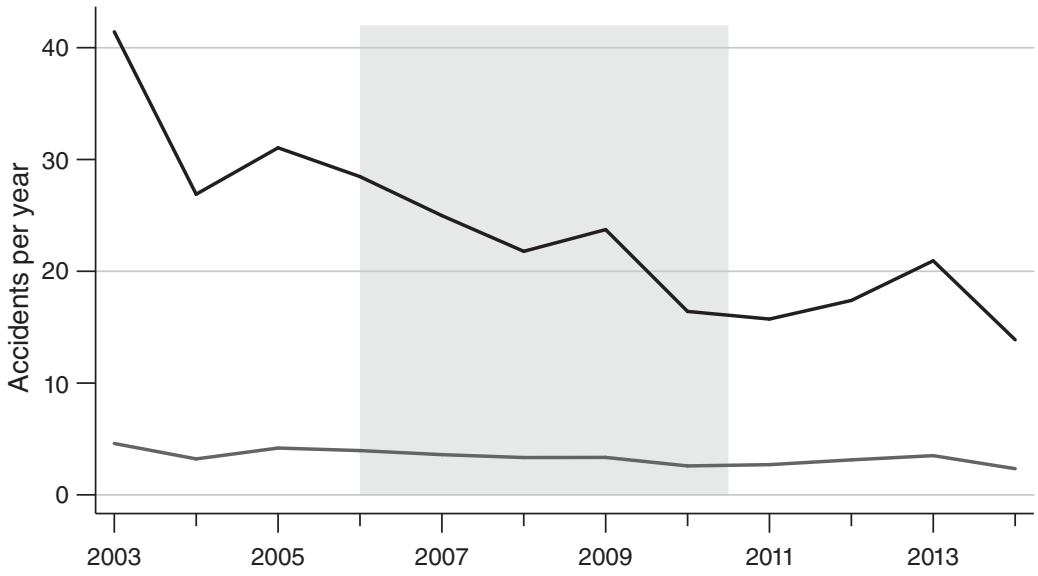

Panel B. San Antonio

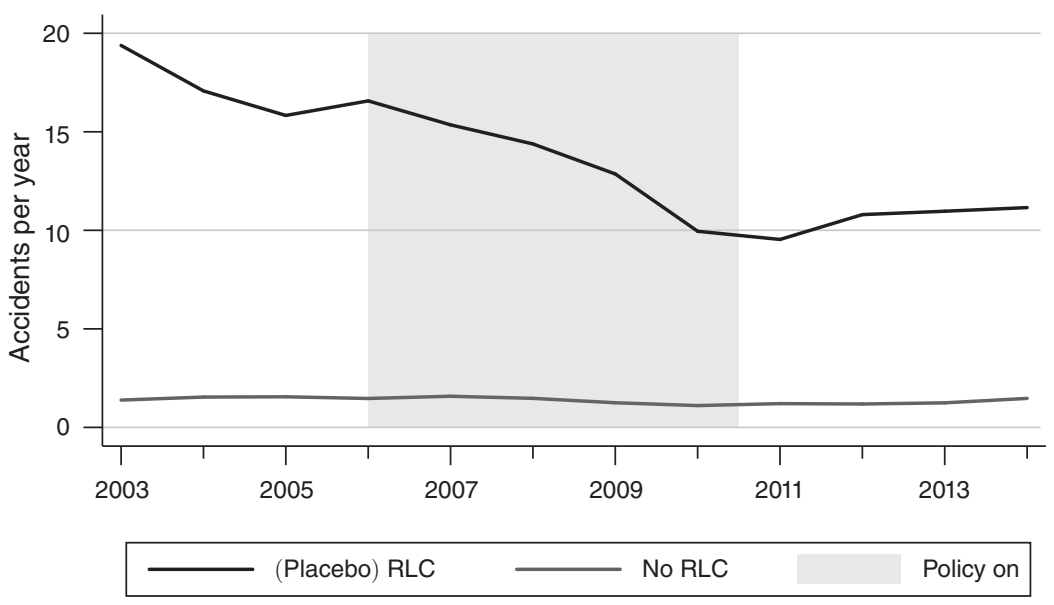

Figure 4. Intersection Vehicle Accident Trends

Notes: The figure plots the average total number of vehicle accidents per intersection by year from 2003-2014. Panel A plots accident levels for the 66 Houston camera intersections in our study as well as Houston intersections with ADT data and at least 1 accident during our panel that did not have a camera. We combine the 20 cameras installed in 2006 and the 46 installed in 2007 into 1 plot. Panel B plots accident levels for two groups of intersections in San Antonio, a city without a camera program. We separately plot the 66 most dangerous intersections from 2003, along with all other San Antonio intersections with ADT data and at least 1 accident during our panel. The most dangerous intersections are determined by assigning each intersection a risk score based on the weighted average of the number of deaths, incapacitating injuries, nonincapacitating injuries, and noninjury accidents from 2003. The data include all accidents within 200 feet from one of the intersections that are classified as "in or related" to the intersection by the police who recorded the accident.

Source: Texas Department of Transportation

accident levels for two groups of intersections in San Antonio, a city without a camera program. We separately plot the 66 most dangerous intersections from 2003, along with all other San Antonio intersections with ADT data and at least one accident during our panel. The most dangerous intersections are determined by assigning each intersection a risk score based on the weighted average of the 
number of deaths, incapacitating injuries, nonincapacitating injuries, and noninjury accidents from 2003. ${ }^{15}$

Panel A provides initial evidence that the introduction of cameras in Houston, and the subsequent removal of the Houston cameras, had no discernible effect on the number of total accidents. If the camera programs are effective at reducing accidents, then we would expect to see a reduction in the number of accidents beginning in the year after cameras are installed (and perhaps during the year of installation). The figure shows no clear trend break in 2006 or 2007 at the time of the camera installations. The average number of intersection accidents peaks in 2003 for the Houston camera group and then decreases at roughly a constant rate from 2005-2008. There is also no clear evidence that ending the program in 2010 led to an increase in the number of accidents. The timing of the increase for the Houston camera group does not correspond with the program end date. Moreover, the overall increase for the Houston camera group toward the end of the panel is similar in magnitude to that of the San Antonio placebo camera group. This suggests that other regional or temporal factors, and not a change in electronic monitoring, are responsible for the slight uptick in accidents in 2012 and 2013.

Panel A also shows two other facts regarding the Houston camera intersections. First, on average, the Houston camera intersections are more dangerous than the Houston noncamera intersections. The average number of total accidents during this period is about five times larger at Houston camera intersections. Second, the Houston camera locations appear to have been chosen based on an unusually large number of accidents in the years prior to the program and, in particular, the number of accidents in 2003. This conclusion is supported by a memo to the then-Chief of Police in early 2006 in which Stein, Levine, and Lomax (2006) advises against using the "Houston Police Department 2003 database" to select camera intersections, as a "longer time period will provide more reliable information on collision causes" (1).

Panel B shows that the most dangerous intersections in San Antonio from 2003 display a similar accident pattern as the Houston camera intersections even though San Antonio never had a camera program. There is approximately a 50 percent reduction in the number of accidents from 2003 to 2010 in both Houston and San Antonio. Figure 4 highlights the challenge in evaluating the effect of electronic monitoring when camera intersections are positively selected on the number of accidents. A simple difference-in-difference model based around the start of the Houston program would overestimate its effectiveness at reducing accidents relative to the Houston no-camera group. The same is true for the empirical Bayes model (see Section III and the online Appendix). For this reason, our focus is on the unexpected removal of the cameras.

\footnotetext{
${ }^{15}$ This weighting scheme is the same as that used to evaluate intersections by Stein, Levine, and Lomax (2006) except that it is applied only to accidents from one year. See online Appendix for details. Stein, Levine, and Lomax (2006) were asked by the Houston Police Department to recommend potential intersections for red-light cameras and provided a list of 100 intersections based on 3 years of accident data. Only six of these intersections were selected.
} 


\section{Selecting the Samples}

We run two main empirical models. The first model estimates the likelihood that a Houston intersection receives a red-light camera. Below we discuss how we use propensity score estimates from the first model to select our treatment and control groups. The second model, as discussed in Section VA, is a difference-in-difference model that exploits the timing of the referendum that shut off the Houston cameras to estimate the causal effect of electronic monitoring on traffic accidents, injury accidents, and traffic patterns.

The intersections considered for our estimating sample in our differences-in-difference model are summarized in Table 2. Our treatment group includes all Houston camera intersections. We use two control groups. The first control group uses Houston intersections that never had a camera and meet our screening criteria (hereafter "Houston sample"). Dallas camera intersections make up the second control group (panel B). The Dallas camera intersections are not subject to the referendum (hereafter "Houston-Dallas sample").

The screening criteria for the within-Houston control group are as follows. First, the control intersection includes at least one intersection-related accident from 2003-2014. We condition on having at least one accident in order to rule out infrequently traveled intersections. This restriction may also exclude intersections that, for whatever reason, appear to be extremely safe and are thus not comparable to camera intersections. Second, the control intersection cannot be within one-half mile of a camera intersection. Previous research suggests that driver reaction to a camera intersection could affect driving behavior at other intersections in close proximity (Shin and Washington 2007, Høye 2013, Wong 2014). We further require that the intersection have nonmissing ADT data for each direction at the intersection. We use the ADT data to control for vehicle traffic levels and test whether traffic patterns at camera intersections change after the installation of a camera.

Next we run a logit model to estimate the likelihood that an intersection would be assigned a Houston camera. As described in further detail below, we use the propensity score estimates from the logit model to determine our final treatment and control samples. We specify our preferred logit model as

$$
y_{i}=\alpha+A_{i t} \gamma+u_{i}
$$

where the dependent variable $y_{i} \in(0,1)$ is the estimated probability that intersection $i$ is a Houston camera intersection. Here, $A_{i t}$ is a vector of pre-referendum intersection traffic accident information, $\alpha$ is an intercept, and $u_{i}$ is an error term which is assumed to have a standard logistic distribution. The pre-referendum years are 2008-2010. The variables included in the vector $A_{i t}$ are motivated by the previous literature and by documents that outline the camera intersection selection process (Stein, Levine, and Lomax 2006; Dallas Police Department 2016; City of Chicago 2015). The vector $A_{i t}$ includes the yearly accident rate at the intersection for each pre-referendum year $t$, for right-angle, non-right-angle, and injury accidents. Note that $A_{i t}$ also includes a variable for red-light-related accidents for each 
Table 2-SAmple AcCident Intersection Characteristics

\begin{tabular}{|c|c|c|c|c|c|c|}
\hline & \multicolumn{3}{|c|}{ All intersections } & \multicolumn{3}{|c|}{ All intersections, trimmed } \\
\hline & $\begin{array}{l}\text { Treatment } \\
\text { (1) }\end{array}$ & $\begin{array}{c}\text { Control } \\
(2)\end{array}$ & $\begin{array}{c}\text { Difference/SD } \\
(3)\end{array}$ & $\begin{array}{l}\text { Treatment } \\
\text { (4) }\end{array}$ & $\begin{array}{l}\text { Control } \\
(5)\end{array}$ & $\begin{array}{c}\text { Difference/SD } \\
(6)\end{array}$ \\
\hline \multicolumn{7}{|c|}{ Panel A. Houston control (2008-2010) } \\
\hline \multicolumn{7}{|c|}{ Accident characteristics } \\
\hline Total & 20.64 & 3.09 & 2.47 & 16.56 & 12.68 & 0.59 \\
\hline Angle & 7.78 & 1.14 & 2.09 & 5.21 & 4.67 & 0.16 \\
\hline Non-angle & 12.86 & 1.95 & 2.37 & 11.35 & 8.01 & 0.60 \\
\hline Injury & 1.89 & 0.34 & 1.59 & 1.38 & 1.03 & 0.27 \\
\hline Red-light running & 6.43 & 0.74 & 2.11 & 3.93 & 3.55 & 0.15 \\
\hline Average daily traffic & 55,268 & 29,705 & 1.42 & 52,475 & 48,864 & 0.16 \\
\hline \multicolumn{7}{|l|}{ Engineering characteristics } \\
\hline Frontage road & 0.82 & 0.01 & 3.31 & 0.75 & 0.04 & 1.50 \\
\hline Lanes & 7.33 & 4.20 & 1.82 & 7.03 & 6.06 & 0.58 \\
\hline Speed limit & 39.93 & 33.32 & 1.37 & 39.75 & 36.06 & 0.81 \\
\hline Divided & 0.92 & 0.70 & 0.49 & 0.97 & 0.89 & 0.28 \\
\hline Number of intersections & 66 & 925 & & 32 & 47 & \\
\hline \multicolumn{7}{|c|}{ Panel B. Houston-Dallas control (2008-2010) } \\
\hline \multicolumn{7}{|c|}{ Accident characteristics } \\
\hline Total & 20.64 & 11.07 & 0.69 & 13.11 & 10.21 & 0.33 \\
\hline Angle & 7.78 & 2.93 & 0.67 & 4.26 & 2.75 & 0.38 \\
\hline Non-angle & 12.86 & 8.14 & 0.55 & 8.85 & 7.46 & 0.21 \\
\hline Injury & 1.89 & 1.43 & 0.23 & 1.21 & 1.18 & 0.02 \\
\hline Red-light running & 6.43 & 2.70 & 0.58 & 3.37 & 2.50 & 0.26 \\
\hline Average daily traffic & 55,268 & 43,881 & 0.59 & 53,044 & 42,175 & 0.58 \\
\hline \multicolumn{7}{|l|}{ Engineering characteristics } \\
\hline Frontage road & 0.82 & 0.33 & 1.02 & 0.75 & 0.38 & 0.76 \\
\hline Lanes & 7.33 & 7.55 & -0.16 & 7.14 & 7.54 & -0.26 \\
\hline Speed limit & 39.93 & 36.19 & 0.85 & 39.75 & 36.15 & 0.83 \\
\hline Divided & 0.92 & 0.85 & 0.25 & 0.89 & 0.83 & 0.17 \\
\hline Number of intersections & 66 & 33 & & 28 & 24 & \\
\hline
\end{tabular}

Notes: The table shows the means for accident and intersection characteristics for the two samples before and after propensity score trimming. Houston camera intersections are the treatment group for both samples. The control groups are Houston noncamera intersections (panel A) and Dallas camera intersections (panel B). The means are taken over the years 2008-2010.

Sources: City of Houston, Google Maps, North Central Texas Council of Governments, Texas Department of Transportation

pre-referendum year and one pre-referendum ADT observation for the Houston sample. ${ }^{16}$ The term $\hat{y}_{i}$ corresponds to each intersection's estimated likelihood, or propensity score, of being a Houston camera intersection (Rosenbaum and Rubin 1983). The propensity score for the Houston-Dallas sample represents the probability that an intersection with those characteristics would be located in Houston.

We use the propensity score to trim the treatment and control groups in each of our samples. We follow Imbens and Wooldridge (2007) and use a simple 0.1 rule to

\footnotetext{
${ }^{16}$ The 2010 data do not include accidents from November and December. We use a more parsimonious logit model for the Houston-Dallas sample that excludes the ADT and red-light-running variables, since the two samples are relatively balanced before trimming and there are fewer Dallas camera intersections than Houston camera intersections. Our difference-in-difference model estimates are similar when we use other logit specifications to select the estimation samples (although the sample sizes are smaller).
} 
drop observations from our sample if the propensity score is outside of the interval $[0.1,0.9]$. Online Appendix Figure 1 shows the distribution of propensity scores in our two main samples. The overlap in the propensity scores for the treatment and control intersections is best for the Houston sample.

Table 2 shows how intersection accident and traffic characteristics vary between our control and treatment groups before and after the sample is trimmed using the propensity score. The top panel displays intersection characteristics for the Houston sample and the bottom panel for the Houston-Dallas sample. Column 3 shows the difference in mean intersection characteristics between the pretrimmed treatment group (column 1) and control group (column 2), normalized by the standard deviation. This approach to evaluating the differences in means allows for a comparison that is not affected by the sample size (Imbens and Wooldridge 2007). We follow Imbens and Wooldridge (2007) and consider the sample to be well balanced for a characteristic if the difference is less than 0.25 standard deviations. Columns $4-6$ repeat the same format as the first three columns for the propensity score-trimmed samples.

The Houston sample is not well balanced in any of the accident characteristics before trimming. The nontrimmed Houston-Dallas sample that already limits the analysis to camera intersections is better balanced than the nontrimmed Houston sample, although it still differs meaningfully on five of the six accident characteristics. After trimming with the propensity score, the accident characteristics are much more similar between treatment and control groups in each sample. Online Appendix Figure 2 shows that the trimmed Houston sample also has reasonable geographic balance in the location of the treatment and control intersections.

In the engineering characteristics, greater differences arise. These characteristics are not included in the propensity score-matching model. Nevertheless, the magnitude difference for the engineering characteristics between control and treatment intersections is generally not large in absolute terms. For example, the speed limit is about three miles per hour greater for the treatment group. The one exception is if an intersection is on a frontage road. A concern could be that drivers might react differently to camera intersections located on frontage and nonfrontage roads. In robustness analysis, we consider a Houston sample comprised only of frontage road intersections. Our model estimate for how the camera program affects the number of total accidents using the Houston frontage road sample is nearly identical to the estimate using our main Houston sample.

Figure 5 shows the difference between accident levels in treatment and control accidents for angle (left) and non-angle (right) accidents in the Houston (top) and Houston-Dallas (bottom) samples. The plotted coefficients are from a regression with year fixed effects and the interaction of year fixed effects with treatment status. The coefficients are normalized relative to 2010. The standard errors from the regression are used to plot the shaded 95 percent confidence intervals. For example, the lower right plot shows the difference in accidents at treatment and control intersections for non-angle accidents in the Houston-Dallas sample. The difference is roughly constant in the three years before treatment, which indicates parallel preremoval trends and supports the key difference-in-difference identifying assumption. The relative gap between treatment and control becomes negative after 2010 . 


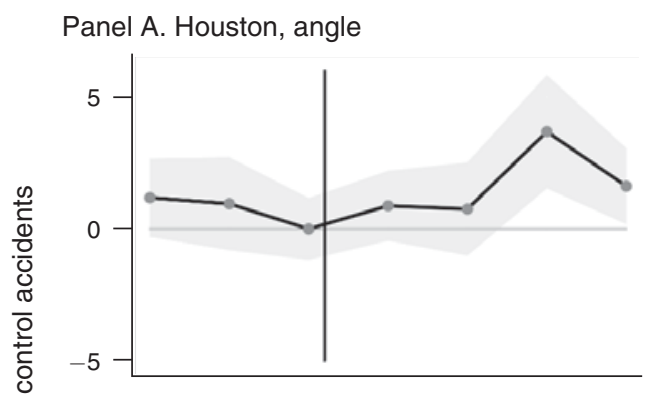

Panel B. Houston, non-angle

Panel C. Houston-Dallas, angle
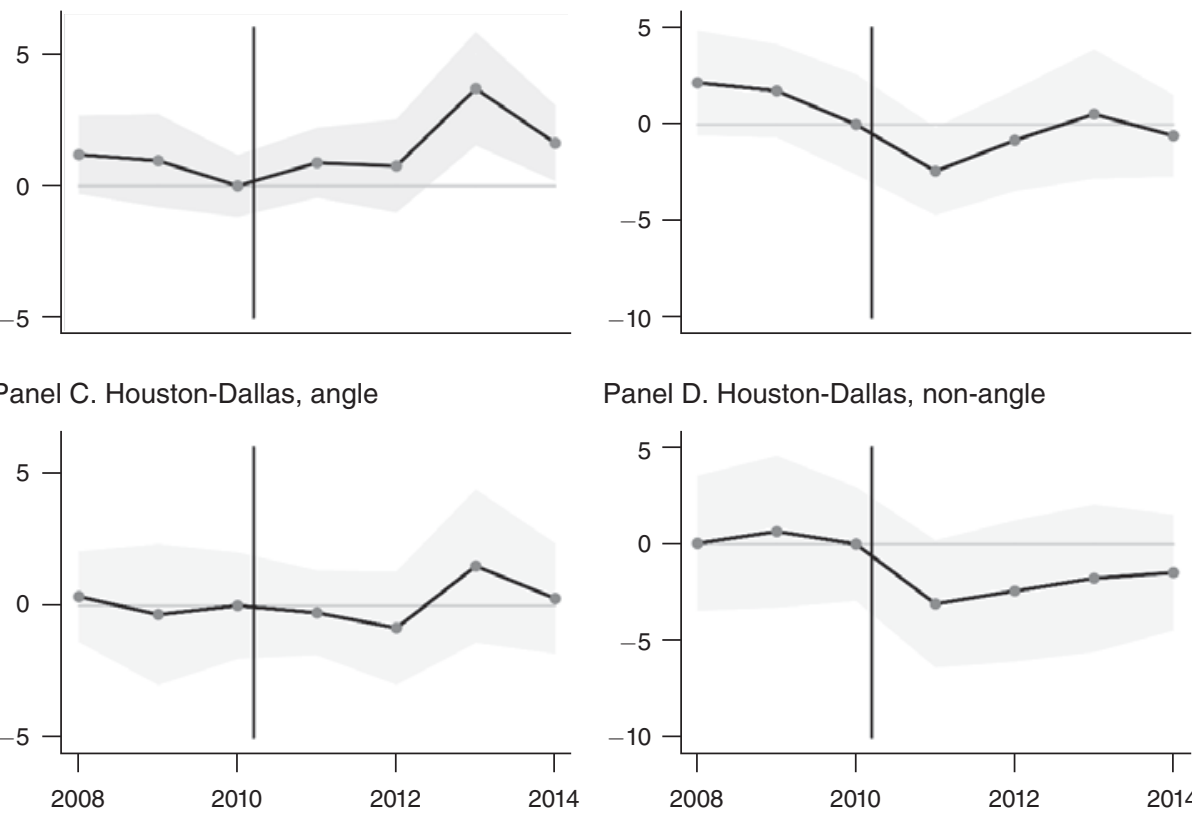

Panel D. Houston-Dallas, non-angle

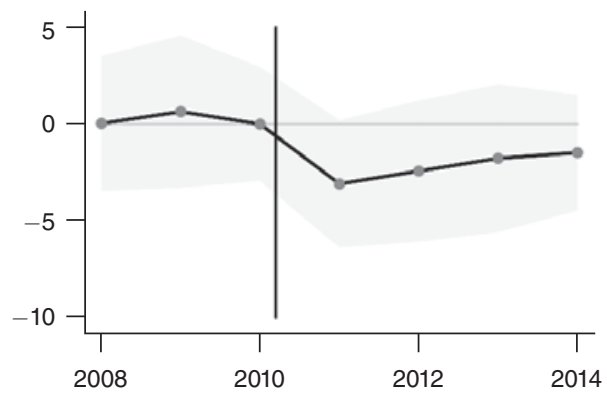

Figure 5. Angle and Non-Angle Accident Trends for Treatment and Control Intersections

Notes: The figure shows the difference between accident levels in treatment and control accidents for angle (left) and non-angle (right) accidents in the Houston (top) and Houston-Dallas (bottom) samples. The plotted coefficients are from a regression with year fixed effects and the interaction of year fixed effects with treatment status. The coefficients are normalized relative to 2010. The standard errors from the regression are used to plot the shaded 95 percent confidence intervals.

Source: Texas Department of Transportation

This provides initial evidence that the number of non-angle accidents decreased at camera intersections when the cameras were turned off. The online Appendix includes a similar figure for total accidents and injury accidents.

Figure 6, panel A shows the pre-referendum level of angle ( $y$-axis) and non-angle ( $x$-axis) accidents for each Houston camera intersection. Intersections in our Houston sample are marked with the black symbols, and those intersections dropped via propensity score trimming with the white symbols. Intersections with relatively low or relatively high (average 2008-2010) accident levels are dropped from the sample. Overall, about 10 percent of the camera intersections average more than 15 angle accidents or 25 non-angle accidents per year. These intersections are all on frontage roads (triangles).

Figure 6 panel B shows the pre-referendum to post-referendum shift in the relative composition of angle and non-angle accidents for each camera intersection. One potential concern is that the camera intersections in our Houston sample may respond differently to the camera program than those intersections dropped from the analysis. Panel B shows that this is not the case. The shift in the accident composition for camera intersections in our sample (black symbols) is similar to that for camera intersections not in our sample (gray symbols), after accounting for yearly 
Panel A. Level of pre-referendum accidents

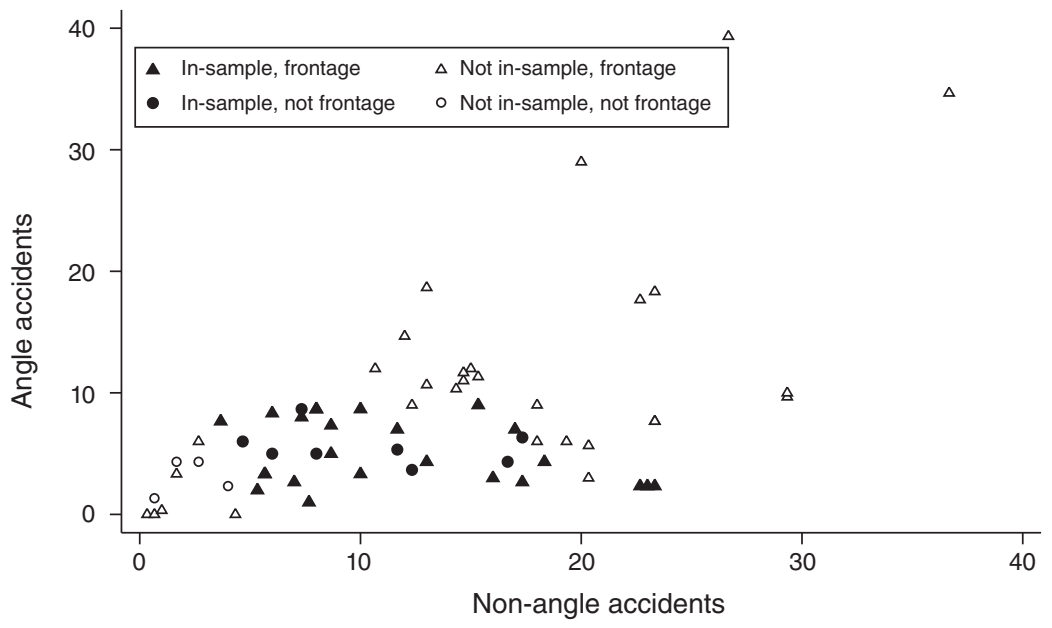

Panel B. Post-referendum shift in accidents

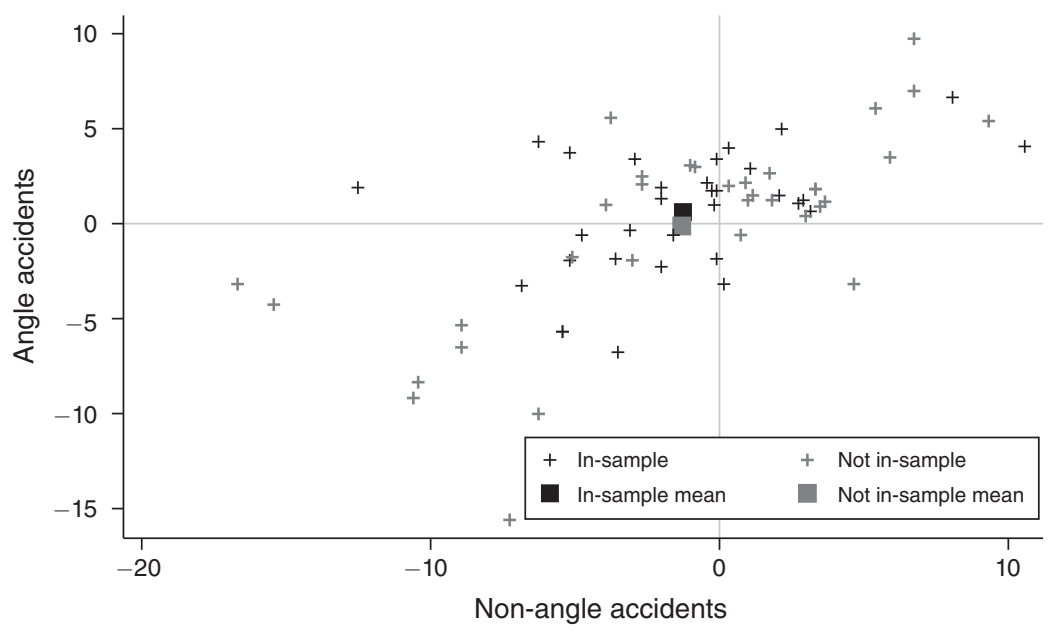

Figure 6. ANGLe AND Non-angle Accidents by CAMERA Intersection

Notes: Panel A shows the pre-referendum level of angle ( $y$-axis) and non-angle ( $x$-axis) accidents for each Houston camera intersection based on whether the intersection is included in the Houston estimation sample and whether the intersection is on a frontage road. Panel B plots the pre-referendum to post-referendum shift in the level of angle and non-angle accidents for each camera intersection after accounting for yearly accident trends and fixed intersection characteristics.

accident trends and fixed intersection characteristics. ${ }^{17}$ On average, there are fewer non-angle accidents for both the in-sample (black square) and not-in-sample (gray square) intersections after the cameras are turned off. The size of the reduction is

\footnotetext{
${ }^{17}$ The figure plots the difference in accident residuals. We calculate the intersection points in three steps. First, we separately estimated a panel regression with the level of angle accidents or non-angle accidents as the dependent variable and year and intersection fixed effects as the dependent variables. Second, we calculate the average pre-referendum (2008-2010) and post-referendum (2011-2014) residual for each intersection. Third, we subtract the average pre-referendum residual from the average post-referendum residual for each intersection.
} 
nearly the same for both groups of intersections. There is a small increase in angle accidents for the in-sample intersections, while there is essentially no change in the number of angle accidents for those intersections not in sample..$^{18}$

\section{The Effect of Removing Red-Light Cameras}

\section{A. Difference-in-Difference Model}

We specify our baseline model as

$$
y_{i t}=\beta_{0}+\beta_{1} T_{i}+\beta_{2} R_{t}+\delta_{1} T_{i} \times R_{t}+\alpha_{i}+v_{t}+\varepsilon_{i t},
$$

where $y_{i t}$ is a particular outcome for intersection $i$ in year $t$. The outcomes we focus on in the paper are total accidents, type of accident (right angle, non-right-angle), whether the accident results in an injury, and ADT at the intersection. The variable $T_{i}$ is an indicator that equals one if the intersection is in Houston and receives a red-light camera. The variable $R_{t}$ is a post-referendum indicator that equals one if the panel observation is from 2011-2014. The term $\delta_{1}$ is the parameter of interest and represents the treatment effect of shutting off the cameras. The model controls for intersection fixed effects $\alpha_{i}$ and year fixed effects $v_{t}$. Standard errors are robust to heteroskedasticity and clustered at the intersection level. We also show a second measure of statistical precision from running a series of permutation tests (randomized inference). 19

The accident information is count data. As such, we estimate the model using a Poisson regression and maximum likelihood estimation. The estimated coefficients can be interpreted as semi-elasticities. We also estimate the model using OLS, which provides very similar (percent change) results. An assumption of the Poisson model is the equivalence between the conditional mean and conditional variance. However, the use of robust standard errors relaxes this assumption (DeAngelo and Hansen 2014).

Table 2 shows that, overall, the accident characteristics are well balanced in both of the trimmed Houston-Dallas and Houston estimation samples. Nevertheless, there are some differences in the means between treatment and control intersections. For this reason, as a robustness check, we also estimate a model that weights the regression by the inverse of the propensity score (Manski and Lerman 1977; Hirano, Imbens, and Ridder 2003). If the propensity score correctly predicts the probability of treatment, then weighting the regression will balance the composition of the covariates that determine treatment.

\footnotetext{
${ }^{18}$ Online Appendix Figure 4 shows the same figure for Houston intersections in the Houston-Dallas sample. The average shift in accidents for in-sample and not-in-sample Houston intersections in our Houston-Dallas sample is very similar to Figure 6.

${ }^{19}$ For each sample and outcome, we randomly allocate the intersections into the treatment and control groups (conditional on maintaining the original group sizes) and calculate the estimated coefficient using our model. We repeat this process 10,000 times for each sample and outcome and use these results to construct confidence intervals and probability values. The tables display the probability value (in brackets) for the null hypothesis that each coefficient is equal to zero and for the null hypothesis that the angle and non-angle coefficients are equal.
} 
The key identifying assumption is that the post-referendum trend for the dependent variable (e.g., angle accidents) for the control intersections is a valid counterfactual for what would have occurred at Houston camera intersections had there been no referendum. The similar pre-referendum trends (2008-2010) shown in Figure 5 support this assumption.

A specific concern regarding the identifying assumption is that a camera program could alter driving behavior at noncamera intersections. Economic theory predicts that some drivers will engage in averting behavior. The longer expected travel times on roads with cameras, along with the higher likelihood of a fine, may lead some drivers to avoid traveling through the camera intersections. If this occurs, then the shift in traffic would likely lead to more accidents at noncamera intersections, and our Houston sample estimates should be viewed as an upper bound on the number of accidents prevented under electronic monitoring. At the same time, if there is uncertainty about the location of the cameras, then drivers may adjust their behavior citywide, as in Ayres and Levitt (1998). If individuals drive slower near all intersections under a camera program (an increase in precautionary driving), then our Houston sample estimates should be viewed as a lower bound.

A partial test of spillovers using Dallas control intersections suggests that treatment spillovers to the control intersections are small. Our Houston-Dallas sample uses control intersections from a different city where there is no reason to expect any spillover effect. These results (see next section) are similar to our Houston sample results. ${ }^{20}$

\section{B. Traffic Accidents}

Table 3 shows the coefficient of interest for the effect of ending the camera program on accident levels using the difference-in-difference model. Panels A and B show estimates for the Houston and Houston-Dallas samples, respectively. We estimate each model separately for angle accidents (column 1), non-angle accidents (column 2), and total accidents (column 3).

We find support for the three main predictions of the behavior model in Section I. First, the model predicts differing treatment effects for the two types of accidents. We can reject equivalence between the coefficient estimates for angle and non-angle accidents. In the Houston sample, the probability value for a null hypothesis that the angle and non-angle accidents are equal is 0.000 .

Second, the model predicts that electronic monitoring will lead to an increase in non-angle accidents. Non-angle accidents will increase when there are cameras, as drivers will trade off a higher accident risk from stopping with the higher expected fine from continuing. When the camera program ends, we estimate a statistically

\footnotetext{
${ }^{20}$ If anything, the Houston-Dallas sample estimates imply a larger net increases in accidents under a camera program. This comports with our view that the averting behavior effect is likely to be larger than the precautionary driving effect. There are at least two reasons. First, Houston posted traffic signs (on all approaching roadways) that indicated the exact location of each camera. Second, we exclude nearby control intersections within a half-mile of a camera intersection from the analysis.
} 
Table 3-The Effect on Accidents from Ending the Camera Program

\begin{tabular}{|c|c|c|c|}
\hline Dependent variable: & $\begin{array}{c}\text { Angle } \\
(1)\end{array}$ & $\begin{array}{c}\text { Non-angle } \\
\text { (2) }\end{array}$ & $\begin{array}{c}\text { Total } \\
(3)\end{array}$ \\
\hline \multicolumn{4}{|l|}{ Panel A. Houston sample } \\
\hline After removal $\times$ treated & $\begin{array}{c}0.258 \\
(0.131) \\
{[0.061]}\end{array}$ & $\begin{array}{r}-0.194 \\
(0.104) \\
{[0.068]}\end{array}$ & $\begin{array}{r}-0.038 \\
(0.098) \\
{[0.702]}\end{array}$ \\
\hline Equality of angle and non-angle, $p$-values: & 0.000 & {$[0.006]$} & \\
\hline Treatment intersections & 32 & 32 & 32 \\
\hline Control intersections & 47 & 47 & 47 \\
\hline \multicolumn{4}{|l|}{ Panel B: Houston-Dallas sample } \\
\hline After removal $\times$ treated & $\begin{array}{c}0.015 \\
(0.176) \\
{[0.935]}\end{array}$ & $\begin{array}{r}-0.312 \\
(0.137) \\
{[0.040]}\end{array}$ & $\begin{array}{r}-0.192 \\
(0.125) \\
{[0.177]}\end{array}$ \\
\hline Equality of angle and non-angle, $p$-values: & 0.072 & {$[0.097]$} & \\
\hline Treatment intersections & 28 & 28 & 28 \\
\hline Control intersections & 24 & 24 & 24 \\
\hline
\end{tabular}

Notes: The table shows the difference-in-difference coefficient of interest for the removal of the Houston cameras from estimating equation (4) using a Poisson model. The dependent variable is the yearly number of angle (column 1), non-angle (column 2), and total accidents (column 3). The Houston sample uses Houston noncamera intersections as the control group. The Houston-Dallas sample uses Dallas camera intersections as the control group. Both samples include all police-reported "intersection-related" accidents within 200 feet of an intersection. Standard errors (in parentheses) are robust to heteroskedasticity and clustered by intersection. The table also displays probability values (in brackets) from a permutation test for the null hypothesis that each coecient is equal to zero. In each panel we test the null hypothesis that the angle and non-angle coefficients are equal using the clustered standard errors and from a permutation test (in brackets).

Source: Texas Department of Transportation

significant decrease in non-angle accidents of 19 percent in the Houston sample and 31 percent in the Houston-Dallas sample. ${ }^{21}$

Third, the model predicts that the reduction in red-light running under the camera program will lead to fewer angle accidents. The size of the reduction in angle accidents will depend on the accident risk of the vehicles that had been running a red light. Previous studies find that without electronic monitoring, the majority of vehicles running a light do so just after the light turns red, when there is a low accident risk (e.g., Yang and Najm 2007). We find modest evidence that the camera program reduced angle accidents. If the electronic monitoring program had been effective at reducing the number of accidents, then we would expect to observe an increase in the number of angle accidents. The coefficient estimate of 26 percent is economically and statistically significant in the Houston sample, but is nearly zero in the Houston-Dallas sample.

There is no evidence that electronic monitoring decreased the number of total accidents. The model in Section I shows that the predicted effect on total accidents is ambiguous and depends on the offsetting effects of the two accident types. We estimate negative and statistically insignificant coefficients for the change in total

\footnotetext{
${ }^{21}$ In robustness analysis we divide the non-angle accidents into five subgroups: head on, single vehicle, turning, rear end, and other. Online Appendix Table 5 shows that the reduction in non-angle accidents is mostly attributable to a reduction in rear-end accidents.
} 
accidents in our Houston ( -4 percent) and Houston-Dallas (-19 percent) samples. ${ }^{22}$ A change in the percentage of non-angle accidents has a larger impact on the overall change in total accidents, since there are nearly twice as many non-angle accidents as angle accidents at an intersection (Table 1, panel B).

Finally, we conduct heterogeneity analysis for the change in angle and non-angle accidents based on the time of day and the day of week (online Appendix Tables 6 and 7). We estimate our model on the subset of accidents occurring during three different daily time periods (day: 9 AM-4 PM, night: 7 PM-7 AM, and rush hour: 7-9 AM and 4-7 PM) and two day-of-week groupings (weekday, weekend). In our Houston sample, all but one of the angle accident coefficients are positive, while five of the six non-angle coefficients are negative. Overall, the estimates are imprecise. Only 3 of the 12 estimated day-of-week-by-time-of-day coefficients are statistically significant at the 5 percent level. The largest estimated increase is for angle accidents during the week at night (39 percent), and the largest estimated decrease is for non-angle accidents on the weekend during rush hour $(-47$ percent $) .{ }^{23}$

\section{Injury Accidents}

We do not find any evidence that electronic monitoring led to a reduction in total accidents. However, it is possible that the change in the composition of accidents under the camera program could result in more injury accidents. Table 1 shows that the typical angle accident is more dangerous than the typical non-angle accident. Moreover, estimating the effect on injuries is important for understanding the overall welfare effect of the camera program.

Table 4 shows estimation results for the effect of ending the camera program on the number of accident-related injuries using our difference-in-difference model. An "injury accident" includes one or more reported injuries or deaths (i.e., excluding the unknown- and possible-injury categories). We separately estimate the effect for injury accidents, incapacitating-injury accidents, and nonincapacitating accidents. Columns 4-6 use the number of annual reported accident-related injuries for each intersection as the dependent variable. These specifications reflect the fact that accidents with multiple people injured are more harmful than accidents in which only one person is injured. We separately analyze different types of injuries to account for the large difference in the economic costs associated with the severity of an injury (e.g., Shin and Washington 2007, Blincoe et al. 2015).

There is no evidence that the electronic monitoring led to fewer accident-related injuries. Estimates from the Houston sample suggest that the camera program may have increased injuries. The point estimates are all negative after the program ends and are marginally statistically significant for a reduction in injury accidents.

\footnotetext{
${ }^{22}$ In robustness analysis we estimate a second Houston sample selected via a logit model that considers preprogram (rather than pre-referendum) accident characteristics. The point estimate for the estimated effect on the number of total accidents ( -3 percent) is very similar to that from our main sample.

${ }^{23}$ The empirical Bayes model leads to extremely precise estimates even when the sample includes just a handful of camera intersections (e.g., Garber et al. 2007, Shin and Washington 2007). As such, studies that use the EB model often report precise heterogeneity estimates along a number of dimensions. However, the EB model prioritizes model precision at the expense of producing estimates robust to mean reversion. Please refer to Section III and online Appendix Section 1 for a lengthy discussion of this point.
} 
Table 4-The Effect on Injuries from Ending the Camera Program

\begin{tabular}{|c|c|c|c|c|c|c|}
\hline \multirow{2}{*}{$\begin{array}{l}\text { Dependent variable: } \\
\text { Injury classification: }\end{array}$} & \multicolumn{3}{|c|}{ Injury accidents } & \multicolumn{3}{|c|}{ People injured } \\
\hline & $\begin{array}{l}\text { All } \\
(1)\end{array}$ & $\begin{array}{c}\text { Incapacitating } \\
(2)\end{array}$ & $\begin{array}{c}\text { Nonincapacitating } \\
\text { (3) }\end{array}$ & $\begin{array}{l}\text { All } \\
(4)\end{array}$ & $\begin{array}{c}\text { Incapacitating } \\
\text { (5) }\end{array}$ & $\begin{array}{c}\text { Nonincapacitating } \\
\text { (6) }\end{array}$ \\
\hline \multicolumn{7}{|l|}{ Panel A. Houston sample } \\
\hline After removal $\times$ treated & $\begin{array}{c}-0.318 \\
(0.171) \\
{[0.068]}\end{array}$ & $\begin{array}{c}-0.627 \\
(0.324) \\
{[0.060]}\end{array}$ & $\begin{array}{c}-0.257 \\
(0.189) \\
{[0.182]}\end{array}$ & $\begin{array}{c}-0.149 \\
(0.221) \\
{[0.505]}\end{array}$ & $\begin{array}{c}-0.414 \\
(0.345) \\
{[0.239]}\end{array}$ & $\begin{array}{c}-0.117 \\
(0.227) \\
{[0.614]}\end{array}$ \\
\hline $\begin{array}{l}\text { Treatment intersections } \\
\text { Control intersections }\end{array}$ & $\begin{array}{l}32 \\
47\end{array}$ & $\begin{array}{l}32 \\
47\end{array}$ & $\begin{array}{l}32 \\
47\end{array}$ & $\begin{array}{l}32 \\
47\end{array}$ & $\begin{array}{l}32 \\
47\end{array}$ & $\begin{array}{l}32 \\
47\end{array}$ \\
\hline $\begin{array}{l}\text { Panel } B . \text { Houston-Dallas } \\
\text { After removal } \times \text { treated }\end{array}$ & $\begin{array}{l}\text { ample } \\
\quad 0.005 \\
(0.230) \\
{[0.985]}\end{array}$ & $\begin{array}{r}-0.464 \\
(0.576) \\
{[0.418]}\end{array}$ & $\begin{array}{c}0.077 \\
(0.236) \\
{[0.764]}\end{array}$ & $\begin{array}{c}0.030 \\
(0.274) \\
{[0.919]}\end{array}$ & $\begin{array}{r}-0.451 \\
(0.597) \\
{[0.446]}\end{array}$ & $\begin{array}{c}0.103 \\
(0.279) \\
{[0.736]}\end{array}$ \\
\hline $\begin{array}{l}\text { Treatment intersections } \\
\text { Control intersections }\end{array}$ & $\begin{array}{l}28 \\
24\end{array}$ & $\begin{array}{l}28 \\
24\end{array}$ & $\begin{array}{l}28 \\
24\end{array}$ & $\begin{array}{l}28 \\
24\end{array}$ & $\begin{array}{l}28 \\
24\end{array}$ & $\begin{array}{l}28 \\
24\end{array}$ \\
\hline
\end{tabular}

Notes: The table shows the difference-in-difference coefficient of interest from estimating equation (4) using a Poisson model on the Houston and Houston-Dallas samples. An injury accident includes one or more injuries or fatalities. Incapacitating accidents include a fatality or incapacitating injury. Nonincapacitating accidents exclude injury accidents with a fatality or incapacitating injury. Columns 4-6 use the number of annual reported accident-related injuries for each intersection as the dependent variable. Standard errors (in parentheses) are robust to heteroskedasticity and clustered by intersection. The table also displays probability values (in brackets) from a permutation test for the null hypothesis that each coefficient is equal to zero.

Source: Texas Department of Transportation

Estimates from the Houston-Dallas sample imply that the overall change in injuries is close to zero.

While the estimated percent change is economically large in some models, the overall change in the number of injury accidents is modest. For example, a decline of 32 percent in injury accidents (panel A, column 1) corresponds to a decrease of approximately 29 injury accidents per year across all camera intersections in Houston after the camera program ends, or about 1 fewer injury accident per 44 million vehicles passing through a camera intersection. ${ }^{24}$

\section{Average Daily Traffic}

The installation of cameras could lead drivers to change where they drive in addition to how they drive. Drivers may choose to alter their driving routes to avoid intersections with cameras as a means to save time or to avoid fines. Online Appendix Table 8 provides some evidence on how average daily traffic at an intersection changes after electronic monitoring ends.

We estimate a simple OLS difference-in-difference model (equation (4) without the fixed effects) for the subset of intersections in our Houston sample that have one pre-referendum and one post-referendum ADT observation. We estimate the model with and without propensity score weights. ${ }^{25}$ The four estimates imply increases of

\footnotetext{
${ }^{24} \mathrm{We}$ calculate the change in the implied number of accidents by taking the product of the point estimate $(-0.318)$, the yearly mean for all treated intersections in the trimmed sample from Table $2(1.38)$, and the number of camera intersections (66). We calculate the reduction in the accident rate as the total amount of annual vehicle traffic at camera intersections divided by the number of avoided injury accidents: $(52,475 \times 365 \times 66) / 29$.

${ }^{25}$ We use the same propensity score weights as those used in the accident analysis.
} 
between 6 percent and 18 percent in traffic at Houston camera intersections after electronic monitoring ended. None of the estimates are statistically significant. We interpret these estimates as suggestive evidence that there may have been a small shift in driving patterns. An increase in traffic at treatment intersections after the referendum would imply an upward bias on the accident estimates in Section VB. The positive accident-point estimates would overestimate the true effect, while the negative estimates would be an underestimate and biased toward zero. ${ }^{26}$

\section{E. Robustness Analysis}

Table 5 shows four robustness specifications. The relevant comparisons are the estimates for accidents in Table 3, panel A and injuries in Table 4, panel A.

Panel A shows OLS estimates that suggest a percentage change and statistical significance similar to those using the Poisson model. Panel B drops 2011 accidents from our analysis. The Houston cameras were temporarily turned back on for one month in 2011 in response to a court ruling that Houston had breached its contract with a private company by turning off the cameras. The results are similar regardless of whether we include 2011 data in our post-referendum period.

Panel $\mathrm{C}$ estimates our model using inverse propensity score weighting (Manski and Lerman 1977; Hirano, Imbens, and Ridder 2003). Overall, Table 2 shows that the accident characteristics are well balanced. There are, however, slightly more non-angle accidents at camera intersections than noncamera intersections during the pre-referendum period (and therefore slightly more total accidents at camera intersections). If the propensity score correctly predicts the likelihood that a Houston intersection has a camera, then reweighting by the propensity score will eliminate selection bias. On the other hand, if the propensity score is not correctly specified, then reweighting could exacerbate underlying selection differences (Freedman and Berk 2008). We do not know the exact selection rule used by Houston officials and view the propensity score as approximating the selection criteria. As such, our preferred specification does not weight by the propensity score. Nevertheless, our estimates are similar under inverse propensity score weighting.

Panel D estimates the model on a sample that only includes frontage road intersections. One potential concern in our main analysis is the lack of frontage road balance between our treatment and control samples. Camera intersections are much more likely to be located on frontage roads. Panel D uses a frontage road sample that does not condition on having ADT information for each intersection. Overall, we estimate a very similar effect on total accidents ( -6 percent) as in our main Houston sample ( -4 percent). Neither estimate is statistically different from zero. ${ }^{27}$

\footnotetext{
${ }^{26}$ There are a number of caveats to the ADT estimates. First, ADT is not measured in the same years for all intersections. Pre-referendum ADT values are measured between 2007-2010, while post-referendum values are measured between 2011-2014. Second, the data are only available for a subsample of intersections in Houston. Third, there is no way to observe whether the ADT trends are similar between treatment and control intersections prior to electronic monitoring. Finally, if there is measurement error in the interpolation procedure used to assign the ADT data to intersections (see online Appendix for details), then the ADT estimates are likely to be attenuated toward zero.

${ }^{27}$ Online Appendix Section 3.2 provides supporting documentation on the frontage road sample.
} 
Table 5-The Effect on Accidents from Ending the Red-Light Camera Program Robustness SPECIFICATIONS

\begin{tabular}{|c|c|c|c|c|}
\hline Dependent variable: & $\begin{array}{l}\text { Angle } \\
(1)\end{array}$ & $\begin{array}{l}\text { Non-angle } \\
\text { (2) }\end{array}$ & $\begin{array}{l}\text { Total } \\
\text { (3) }\end{array}$ & $\begin{array}{l}\text { Injury } \\
(4)\end{array}$ \\
\hline \multicolumn{5}{|l|}{ Panel A. OLS } \\
\hline After removal $\times$ treated & $\begin{array}{l}1.025 \\
(0.688) \\
{[0.080]}\end{array}$ & $\begin{array}{r}-2.120 \\
(0.979) \\
{[0.016]}\end{array}$ & $\begin{array}{c}-1.090 \\
(1.385) \\
{[0.357]}\end{array}$ & $\begin{array}{r}-0.379 \\
(0.255) \\
{[0.106]}\end{array}$ \\
\hline Percent change & 13.2 & -16.5 & -5.3 & -20.0 \\
\hline Equality of angle and non-angle, $p$-value & 0.001 & {$[0.000]$} & & \\
\hline Treatment intersections & 32 & 32 & 32 & 32 \\
\hline Control intersections & 47 & 47 & 47 & 47 \\
\hline \multicolumn{5}{|l|}{ Panel B. Drop 2011} \\
\hline After removal $\times$ treated & $\begin{array}{l}0.307 \\
(0.141) \\
{[0.035]}\end{array}$ & $\begin{array}{c}-0.129 \\
(0.106) \\
{[0.228]}\end{array}$ & $\begin{array}{c}0.022 \\
(0.103) \\
{[0.825]}\end{array}$ & $\begin{array}{l}-0.275 \\
(0.194) \\
{[0.156]}\end{array}$ \\
\hline Equality of angle and non-angle, $p$-value & 0.001 & {$[0.006]$} & & \\
\hline Treatment intersections & 32 & 32 & 32 & 32 \\
\hline Control intersections & 47 & 47 & 47 & 47 \\
\hline \multicolumn{5}{|l|}{ Panel C. Propensity score weighted } \\
\hline After removal $\times$ treated & $\begin{array}{l}0.256 \\
(0.127) \\
0.097]\end{array}$ & $\begin{array}{c}-0.239 \\
(0.115) \\
{[0.069]}\end{array}$ & $\begin{array}{c}-0.061 \\
(0.101) \\
{[0.599]}\end{array}$ & $\begin{array}{r}-0.356 \\
(0.166) \\
{[0.039]}\end{array}$ \\
\hline Equality of angle and non-angle, $p$-value & 0.000 & {$[0.004]$} & & \\
\hline Treatment intersections & 32 & 32 & 32 & 32 \\
\hline Control intersections & 47 & 47 & 47 & 47 \\
\hline \multicolumn{5}{|l|}{ Panel D. Frontage } \\
\hline After removal $\times$ treated & $\begin{array}{l}-0.137 \\
(0.158) \\
{[0.395]}\end{array}$ & $\begin{array}{c}-0.006 \\
(0.131) \\
{[0.965]}\end{array}$ & $\begin{array}{c}-0.057 \\
(0.132) \\
{[0.666]}\end{array}$ & $\begin{array}{r}-0.298 \\
(0.183) \\
{[0.107]}\end{array}$ \\
\hline Equality of angle and non-angle, $p$-value & 0.818 & {$[0.346]$} & & \\
\hline Treatment intersections & 40 & 40 & 40 & 40 \\
\hline Control intersections & 50 & 50 & 50 & 50 \\
\hline
\end{tabular}

Notes: The table shows four robustness specifications. The estimates in this table are comparable to those from Table 3, panel A, and Table 4, panel A, column 1. Panel A of this table estimates the same model using OLS. Panel B excludes data from 2011. Panel C uses inverse propensity score weighting. Panel D limits analysis to camera and noncamera observations that are on frontage roads. Standard errors (in parentheses) are robust to heteroskedasticity and clustered by intersection. The table also displays probability values (in brackets) from a permutation test for the null hypothesis that each coefficient is equal to zero. In each panel we test the null hypothesis that the angle and non-angle coefficients are equal using the clustered standard errors and from a permutation test (in brackets).

Source: Texas Department of Transportation

Our strategy to estimate the effect of the cameras on the number of accidents is to use the voter referendum as a natural experiment. At the same time, since our panel of accident data begins in 2003, we are also able to estimate the introduction of the Houston cameras in 2006 and 2007. We estimate a difference-in-difference model on two different samples using camera introduction as the treatment. The samples differ based on how we use a propensity score model to select the samples. The estimates imply that turning on the cameras reduced the number of overall traffic 
accidents by about 30 percent. This finding is in contrast to our camera removal estimates that leverage the exogenous referendum. ${ }^{28}$

However, the introduction results are not too surprising given our results from a placebo camera program simulation analysis. An analysis of the introduction of a placebo camera program using a difference-in-difference model suggests that there is a large (39 percent to 58 percent) and statistically significant reduction in total accidents attributable to a (nonexistent) camera program. As with the actual Houston camera program, placebo "treatment" intersections are selected based on the level of intersection accidents in the years just prior to the program. In our view, these results highlight the challenge in overcoming the mean reversion bias caused by estimating a model where treatment is the endogenous camera introduction. ${ }^{29}$

\section{Social Welfare Analysis}

\section{A. Conceptual Framework}

In this section we outline a framework to interpret how electronic monitoring at traffic intersections affects social welfare. Our discussion closely follows Chalfin and McCrary (2018). ${ }^{30}$

We assume that there are $n$ identical individuals, all of whom drive, and that the social planner maximizes the expected utility of the representative agent. Let $\phi_{j}(R)$ be the probability of experiencing accident outcome $j$ (i.e., fatality, injury, vehicle damage) when a city has $R$ red-light cameras. Define $k_{j}$ as the average cost of outcome $j$. We write expected accident costs as $C \equiv C(R)=\sum_{j=1}^{N} k_{j} \phi_{j}(R)$.

Time delays associated with the camera program, $T$, are an additional cost. We model the cost of the time delay as $T \equiv T(R)=\sigma w m R$, where $w$ is wage, $m$ are the average number of minutes delayed per person per camera, and $\sigma$ is a multiplier on the value of a driver's time. Multiplier $\sigma$ captures two effects: the fraction of the wage at which a driver values travel time and a delay multiplier that reflects the observation that travelers dislike waiting in traffic (e.g., Parry and Small 2009, Anderson 2014).

Define $y(R)=A-\tau$ as consumption when there are no direct accident-related costs. Now, $A$ is assets and $\tau$ is the per-person lump-sum tax equal to the cost of running the camera program. Let $\tau=(r R) / n$, where $r$ is the per-camera cost of the program and $n$ is the city's population. Importantly, we define $r$ as the per-camera administrative cost less the benefit of raising revenue via lump-sum camera fines. The camera program introduces a new means for a city to raise revenue that avoids the negative marginal welfare effects of other fiscal taxes (e.g., income, sales, and property). We assume that every dollar raised via the camera program reduces a

\footnotetext{
${ }^{28}$ Online Appendix Section 3.1 provides details on the introduction analysis.

${ }^{29}$ Online Appendix Section 1.3.1 describes the placebo program simulation in detail.

${ }^{30}$ There are four main differences between the models. First, Chalfin and McCrary (2018) models the size of the police force. Second, our model includes the cost of travel time delays associated with the camera program. Third, our model includes the marginal benefit of revenue raised through fines levied on individuals breaking the law (as compared to other fiscal revenue sources). Fourth, we use the model to evaluate the extensive margin of having a camera program (66 Houston cameras cover at most 7 percent of the city's major intersections) (see Table 2). As such, we consider the social welfare comparative static derived from the model as an approximation.
} 
dollar raised via other distortionary fiscal taxes. Barrage (2016) surveys the literature on the marginal cost of public funds (MCF) and calculates that a dollar raised via fiscal taxes has a MCF of 1.49. In our analysis, for every dollar raised by the camera program, we subtract 49 cents from the cost of running the program. Now,

$$
V(R)=y(R)-C(R)-T(R) .
$$

Social welfare is maximized when the first derivative of equation (5) is zero. Social welfare will improve under an expansion of the electronic monitoring program if $V^{\prime}(R)>0$. We can use this first-order condition to derive a simple comparative static, equation (6), to evaluate whether a change in the number of cameras is welfare improving: ${ }^{31}$

$$
|\varepsilon|>\frac{r R+n T}{n C} .
$$

Here, $\varepsilon=\left(\sum_{j=1}^{N} k_{j} \phi_{j}(R) \varepsilon_{j}\right) /\left(\sum_{j=1}^{N} k_{j} \phi_{j}(R)\right)$ is an aggregate elasticity equal to the cost-weighted sum of the accident outcome elasticities $\varepsilon_{j}$. The right-hand side of the inequality is a ratio of the total dollar costs under electronic monitoring to the total expected accident costs. Electronic monitoring of traffic intersections improves welfare if it passes the cost-benefit test in equation (6). The cost-weighted improvement in accident safety under electronic monitoring must exceed the ratio of program costs to accident costs in order for electronic monitoring to be welfare improving.

The camera program should be revised or suspended if $\varepsilon>0$ or if $\varepsilon<0$ but does not satisfy equation (6). When $\varepsilon>0$, electronic monitoring increases accident costs (i.e., the benefit is negative). One exception to the decision rule given by equation $(6)$ is if the improvement in accident safety $(\varepsilon<0)$ does not satisfy the inequality but the program allows for other law enforcement resources (e.g., police officers) to be used more effectively. We return to this possibility after evaluating the baseline model.

\section{B. The Houston Camera Program and Social Welfare}

Online Appendix Table 11 shows camera program and traffic accident statistics for Houston. The information in the table can be used, along with equation (6), to evaluate whether the camera program had positive welfare effects.

The average annual cost to operate each camera in 2009 and 2010 (excluding fixed costs) is $\$ 85,000$. As discussed above, this is a "net" cost that takes into account the estimated welfare value of raising revenue from a lump-sum tax. We follow the recent literature and set the value of a driver's time at half the average wage (Anderson 2014). In our conservative baseline analysis, we do not take into account evidence that individuals value their time more when stuck in traffic (Small and Verhoef 2007) or recent research suggesting that the value of time may

\footnotetext{
${ }^{31} \mathrm{We}$ assume that all citizens drive and each driver is a potential offender and victim, utility is linear (Chetty 2006), and $\phi_{j}$ is differentiable and strictly convex. The key step in solving for equation (6) is multiplying the first order condition by $R / C$.
} 
be nonlinear and substantially higher in urban areas during rush hour traffic (Bento, Roth, and Waxman 2017).

We calculate the number of minutes delayed by multiplying the length of the average red light at 1 of the 66 camera intersections by the estimated number of additional vehicles that stop under the camera program (rather than continue through the light). Our baseline estimate is very conservative, as it is estimated only off of red-light violations and assumes that no vehicles stop rather than pass through the yellow light. The accident injury risk rates are calculated over the camera intersections using data for the two years prior to the referendum that shut off the cameras. We estimate the accident-related injury elasticities using our difference-in-difference model. Accident injury costs are provided by the National Highway Traffic Safety Administration and include direct injury costs (e.g., hospital), economic costs (e.g., lost wages), and quality of life costs (Blincoe et al. 2015). We use the Department of Transportation's recommended value of statistical life, $\$ 8,860,000$, as the cost of a fatal accident (Blincoe et al. 2015). The expected annual accident cost for a Houston resident attributable to the 66 camera intersections during the last 2 years of the camera program is $\$ 73$. Eighteen percent of this figure is the result of the 4 fatalities at these intersections during this period. ${ }^{32}$

The top panel in Table 6 shows the cost-weighted elasticity using the injury coefficients from our model. The cost-weighed elasticity is 0.139 when we use our point estimates. In other words, our point estimates imply that the camera program led to an increase in accident injury-related costs and had a negative welfare effect-even before accounting for the costs of running the program. The injury estimates, though, are imprecise. The 90 percent confidence interval for the cost-weighted elasticity is $[-0.202,0.479]$.

The bottom panel of Table 6 shows several different program cost to accident cost ratios. Recall that the camera program is welfare improving if the absolute value of the cost-weighted injury elasticity is greater than the ratio of program cost to accident costs. Our conservative baseline cost ratio is 0.163 . If we evaluate social welfare using the lower bound of the 90 percent confidence interval and the conservative cost ratio, then we would conclude that the camera program is welfare improving $(|-0.202|>0.163)$.

However, the baseline cost ratio makes two assumptions that bias toward concluding that the camera program improves welfare. First, the baseline cost ratio calculates the number of vehicles stopping under a camera program as only those vehicles that would have run a red light. The ratio increases to 0.267 when we assume that there are just as many vehicles stopping under the camera program that would have passed through the intersection while the light was still yellow. Second, if we follow the previous literature and incorporate a value of time delay multiplier (for time spent sitting in traffic), then the cost ratio increases to 0.247 from the

\footnotetext{
${ }^{32}$ All dollar estimates in the table are in 2010 dollars. We multiply our regression point estimates by -1 to make the elasticity estimates more intuitive (since we estimate the response to a reduction in cameras, i.e., ending the program). We assume that the fatality elasticity is the same as for incapacitating injuries. The online Appendix provides further details on how each statistic is calculated and additional information on the data sources.
} 
Panel A. Cost-weighted elasticity estimates [LHS of equation (6)]

Point estimate $[90$ percent confidence interval]

0.139

$[-0.202,0.479]$

Panel B. Program-cost-to-accident-cost ratios [RHS of equation (6)]

Conservative baseline

0.163

More comprehensive alternatives:

(a) Include deterred yellow-light vehicles

0.267

0.247

(b) Include delay multiplier in $[\sigma]$ (Parry and Small 2009, Anderson 2014)

(c) Incorporate yellow-light vehicles and delay multiplier

Notes: The top panel of the table calculates cost-weighted elasticity estimates using the estimated injury elasticities from our preferred model. The bottom panel of the table calculates the program-cost-to-accident-cost ratio. Our conservative baseline ratio uses the parameter values from online Appendix Table 11. The baseline cost ratio makes two important assumptions that bias toward concluding that the camera program improves welfare. In (a) we incorporate an estimate for vehicles stopping that could actually have made it through the light before it turned red. In (b) we follow previous literature and incorporate a value of time delay multiplier for time spent sitting in traffic. In (c) we take into account both deterred yellow-light vehicles and the delay multiplier.

baseline value. ${ }^{33}$ If we adjust our baseline cost ratio by including both deterred yellow-light vehicles and the delay multiplier, then the cost ratio becomes 0.435 . We view each of the alternative cost ratios as more realistic and comprehensive as compared to our conservative baseline cost ratio. These comprehensive cost ratios provide greater evidence that the Houston camera program did not improve social welfare. The camera program fails to improve welfare if we use the 90 percent lower bound estimate for the cost-weighted elasticity. ${ }^{34}$

The welfare analysis is fairly insensitive to how we handle fatalities. On average, there are two fatalities per year during the program and two fatalities per year after the end of the program. The welfare conclusion remains unchanged whether we use a lower VSL estimate or completely ignore fatalities in equation (6). Online Appendix Table 12 shows how the cost-weighted elasticity estimates and the program-cost-toaccident-cost ratios change when we vary the values used for key parameters. For example, assuming that the red-light wait times or the annual change in the number of cars waiting are one standard deviation lower leads to a somewhat more favorable view of the camera program (but contradicts the traffic data used to set the baseline values). Nevertheless, we still conclude that the camera program did not improve social welfare at the 90 percent confidence level when we use these lower values in our most comprehensive program-cost-to-accident-cost ratio estimate (Table 6 row (c)). The larger challenge to analyzing social welfare is that the year-to-year variability in traffic accidents, when combined with the low frequency of the most costly injuries, leads to imprecise regression estimates.

Finally, it is possible that an electronic monitoring program could fail to satisfy equation (6) but still improve social welfare for the city. This scenario would include, for example, a reduction in cost-weighted accident injuries and a reallocation of

\footnotetext{
${ }^{33}$ We follow Parry and Small (2009) and Anderson (2014) and use a value of 1.8 for the delay multiplier. In our setting, the additional travel time occurs from waiting in traffic at a red light. As such, we can capture the delay multiplier in the same parameter as the value of time, and $\sigma=1.8 \times 0.5=0.9$.

${ }^{34}$ If we incorporate yellow-light vehicles and the delay multiplier, then the camera program fails to improve welfare using the 95 percent lower bound estimate for the cost-weighted elasticity $(|-0.268|<0.435)$.
} 
the law enforcement personnel previously dedicated to intersection monitoring to another welfare-improving activity. ${ }^{35}$

There is no evidence of a significant reallocation of police resources related to traffic signal enforcement after the Houston camera program ends. The average number of red-light-running citations issued by police per year during the last 3 years of the camera program (2008-2010) is 18,738 . In the subsequent 4 years, law enforcement personnel issued an average of 16,998 tickets per year (2011-2014). The 9 percent reduction in citations implies that, if anything, police reallocate time away from monitoring intersections when the camera program ends.

\section{Conclusion}

Electronic monitoring of traffic intersections is a common policy to enforce traffic laws in the United States. The stated goal of red-light camera programs is to reduce cross-road collisions and to improve public safety. However, a simple crime deterrence model predicts that a camera program will decrease angle accidents while increasing non-angle accidents. An increase in non-angle accidents under a camera program is not an incidental or anomalous outcome. The underlying mechanism is that drivers will knowingly trade off a higher accident risk from stopping in order to avoid the expected fine of running a red light. Whether a camera program improves safety is an empirical question.

One challenge in estimating the effect of electronic monitoring on vehicle accidents is that intersections with cameras are likely to be among the most dangerous intersections in the city. Moreover, the start of electronic surveillance is endogenous and could follow a spike in accidents at the intersection. We show that both empirical challenges are true in Houston, Texas.

We estimate a difference-in-difference model using 12 years of geocoded police accident data and find evidence that angle accidents increased and non-angle accidents decreased in Houston after ending the camera program. We avoid the endogenous start of a camera program by examining driver behavior after the cameras are unexpectedly shut off via a voter referendum. The effect on total accidents is close to zero and statistically insignificant. We adapt the social welfare model of Chalfin and McCrary (2018), which allows us to incorporate the fact that some types of accidents are more dangerous than others. The social welfare impact of Houston's camera program is negative when we use the accident-related injury point estimates from our preferred model. We conclude, with approximately 90 percent certainty, that the Houston program did not improve social welfare. Nevertheless, the year-to-year variability in traffic accidents within a city, combined with the low frequency of the most serious injuries, makes definitive analysis of social welfare difficult.

\footnotetext{
${ }^{35}$ The welfare gain from the new activity would need to be larger than the gap between the left- and right-hand sides of equation $(6):((r R+n T) / n C)-|\varepsilon|$.
} 


\section{REFERENCES}

Abbess, Christopher, Daniel Jarrett, and Catherine C. Wright. 1981. "Accidents at Blackspots: Estimating the Effectiveness of Remedial Treatment, with Special Reference to the 'Regression-to-Mean' Effect." Traffic Engineering and Control 22 (10): 535-42.

-Anderson, Michael L. 2014. "Subways, Strikes, and Slowdowns: The Impacts of Public Transit on Traffic Congestion." American Economic Review 104 (9): 2763-96.

-Angrist, Joshua D., and Jörn-Steffen Pischke. 2017. "Undergraduate Econometrics Instruction: through Our Classes, Darkly." Journal of Economic Perspectives 31 (2): 125-44.

-Apel, Robert. 2013. "Sanctions, Perceptions, and Crime: Implications for Criminal Deterrence." Journal of Quantitative Criminology 29 (1): 67-101.

- Ayres, Ian, and Steven D. Levitt. 1998. "Measuring Positive Externalities from Unobservable Victim Precaution: An Empirical Analysis of Lojack." Quarterly Journal of Economics 113 (1): 43-77.

Barrage, Lint. 2016. "Optimal Dynamic Carbon Taxes in a Climate-Economy Model with Distortionary Fiscal Policy: Online Appendix." Review of Economic Studies 87 (1): 1-39.

Becker, Gary S. 1968. "Crime and Punishment: An Economic Approach." Journal of Political Economy 76 (2): 169-217.

Bento, Antonio M., Kevin Roth, and Andrew Waxman. 2017. "The Value of Urgency, Evidence from Congestion Pricing Experiments." https://economics.stanford.edu/sites/g/files/sbiybj9386/f/bento. pdf.

Blincoe, Lawrence, Ted R. Miller, Eduard Zaloshnja, and Bruce A. Lawrence. 2015. The Economic and Societal Impact of Motor Vehicle Crashes, 2010 (Revised). Washington, DC: Department of Transportation, National Highway Traffic Safety Administration.

-Chalfin, Aaron, and Justin McCrary. 2017. "Criminal Deterrence: A Review of the Literature.” Journal of Economic Literature 55 (1): 5-48.

Chalfin, Aaron, and Justin McCrary. 2018. "Are U.S. Cities Underpoliced? Theory and Evidence." Review of Economics and Statistics 100 (1): 167-86.

-Chen, Greg, and Rebecca N. Warburton. 2006. "Do Speed Cameras Produce Net Benefits? Evidence from British Columbia, Canada." Journal of Policy Analysis and Management 25 (3): 661-78.

Chetty, Raj. 2006. "A General Formula for the Optimal Level of Social Insurance." Journal of Public Economics 90 (10-11): 1879-1901.

City of Chicago. 2015. "Chicago Red-Light Enforcement Program Intersection Prioritization Steps." City of Chicago. https://www.chicago.gov/city/en/depts/cdot/supp_info/red-light_ cameraenforcement.html (accessed May 2015).

City of Houston. 2017. "Traffic Counts." Open Data Houston. http://data.houstontx.gov/dataset/trafficcounts (accessed October 2017).

Dallas Police Department. 2016. "SafeLight Dallas Stops on Red." Dallas Police Department. http:// southwest.dallaspolice.net/dpdinfo/safelight.html (accessed May 11, 2016).

DeAngelo, Gregory, and Benjamin Hansen. 2014. "Life and Death in the Fast Lane: Police Enforcement and Traffic Fatalities." American Economic Journal: Economic Policy 6 (2): 231-57.

Economist. 2015. "Road Kill." July 4.

-Erke, Alena. 2009. "Red Light for Red-Light Cameras?: A Meta-analysis of the Effects of Red-Light Cameras on Crashes." Accident Analysis and Prevention 41 (5): 897-905.

-Freedman, David A., and Richard A. Berk. 2008. "Weighting Regressions by Propensity Scores." Evaluation Review 32 (4): 392-409.

Garber, Nicholas J., John S. Miller, R. Elizabeth Abel, Saeed Eslambolchi, and Santhosh K. Korukonda. 2007. The Impact of Red Light Cameras (Photo-Red Enforcement) on Crashes in Virginia. Charlottesville: Virginia Transportation Research Council.

Garrett, Jerry. 2011. "Houston City Council Votes to Shut off Red-Light Cameras." New York Times, August 26. https://wheels.blogs.nytimes.com/2011/08/26/houston-city-council-votes-to-shut-offred-light-cameras/.

- Gazis, Denos, Robert Herman, and Alexei Maradudin. 1960. "The Problem of the Amber Signal Light in Traffic Flow." Operations Research 8 (1): 1-157.

Goldenbeld, Charles, Stijn Daniels, and Govert Schermers. 2019. "Red Light Cameras Revisited. Recent Evidence on Red Light Camera Safety Effects." Accident Analysis and Prevention 128: 139-47.

Governors Highway Safety Association (GHSA). 2016. "State Highway Safety Group Supports Red Light Cameras." Statement for attribution to GHSA Executive Director Jonathan Adkins, Washington, DC. 
Hassan, Anita. 2006. "More Houston Red Light Cameras Start Snapping." Houston Chronicle, November 13. https://www.chron.com/news/houston-texas/article/More-Houston-red-lightcameras-start-snapping-1515598.php.

-Hauer, Ezra. 1986. "On the Estimation of the Expected Number of Accidents." Accident Analysis and Prevention 18 (1): 1-12.

-Hauer, Ezra. 1992. "Empirical Bayes Approach to the Estimation of 'Unsafety': The Multivariate Regression Method." Accident Analysis and Prevention 24 (5): 457-77.

Hauer, Ezra. 1997. Observational Before-After Studies in Road Safety: Estimating the Effect of Highway and Traffic Engineering Measures on Road Safety. Bingley, UK: Emerald Group Publishing Limited.

-Hauer, Ezra, Douglas W. Harwood, Forrest M. Council, and Michael S. Griffith. 2002. "Estimating Safety by the Empirical Bayes Method: A Tutorial." Transportation Research Record 1784 (1): 126-31.

- Hirano, Keisuke, Guido W. Imbens, and Geert Ridder. 2003. "Efficient Estimation of Average Treatment Effects Using the Estimated Propensity Score." Econometrica 71 (4): 1161-89.

Houston Chronicle. 2010. "Red-Light Cameras: For." September 5. Houston Chronicle. https://www.chron.com/opinion/recommendations/article/Red-light-cameras-For-1716003.php.

Houston Mayor's Office. 2012. "City of Houston Negotiates End to Red Light Camera Vendor Lawsuit." Houston Mayor's Office, Press Release.

- Høye, Alena. 2013. "Still Red Light for Red Light Cameras? An Update." Accident Analysis and Prevention 55: 77-89.

- Hu, Wen, and Jessica B. Cicchino. 2017. "Effects of Turning On and Off Red Light Cameras on Fatal Crashes in Large U.S. Cities." Journal of Safety Research 61: 141-48.

-Hurwitz, David S., Michael A. Knodler, Jr., and Bruce Nyquist. 2011. "Evaluation of Driver Behavior in Type II Dilemma Zones at High-Speed Signalized Intersections." Journal of Transportation Engineering 137 (4): 277-86.

Imbens, Guido, and Jeffery Wooldridge. 2007. "What's New in Econometrics." Lecture presented at the NBER Summer Institute 2007 Methods Lectures, July 30.

Insurance Institute for Highway Safety (IIHS). 2016. "Red Light Running." IIHS. https://www.iihs. org/topics/red-light-running.

Jensen, Derek. 2010. "After Election, Houston's Red Light Cameras Go Dark." Transportation Nation, November 15. https://www.wnyc.org/story/282900-voters-slam-the-brakes-on-houstons-red-lightcameras/.

Kapoor, Sacha, and Arvind Magesan. 2014. "Paging Inspector Sands: The Costs of Public Information.” American Economic Journal: Economic Policy 6 (1): 92-113.

Ko, Myunghoon, Srinivas Reddy Geedipally, and Troy Duane Walden. 2013. "Effectiveness and Site Selection Criteria for Red Light Camera Systems." Transportation Research Record 2327 (1): 53-60.

-Ko, Myunghoon, Srinivas Reddy Geedipally, Troy Duane Walden, and Robert Carl Wunderlich. 2017. "Effects of Red Light Running Camera Systems Installation and Then Deactivation on Intersection Safety." Journal of Safety Research 62: 117-26.

- Langland-Orban, Barbara, Etienne E. Pracht, and John T. Large. 2014. "Red Light Cameras Unsuccessful in Reducing Fatal Crashes in Large US Cities." Health Behavior and Policy Review 1: 72-81.

Levitt, Steven D. 1997. "Using Electoral Cycles in Police Hiring to Estimate the Effects of Police on Crime." American Economic Review 87 (3): 270-90.

Levitt, Steven D., and Thomas J. Miles. 2006. "Economic Contributions to the Understanding of Crime." Annual Review of Law and Social Science 2: 147-64.

Lord, Dominique, and Srinivas Reddy Greedipally. 2014. Safety Effects of the Red-Light Camera Enforcement Program in Chicago, Illinois. Chicago: Chicago Tribune.

Mahmassani, Hani S., Joseph L. Schofer, Breton L. Johnson, Omer Verbas, Amr Elfar, Archak Mittal, and Marija Ostojic. 2017. Chicago Red Light Camera Enforcement: Best Practices \& Program Road Map. Evanston, IL: Northwestern University Transportation Center.

- Manski, Charles F., and Steven R. Lerman. 1977. "The Estimation of Choice Probabilities from Choice Based Samples." Econometrica 45 (8): 1977-88.

-Martinez, Kristie L. Hebert, and Bryan E. Porter. 2006. "Characterizing Red Light Runners Following Implementation of a Photo Enforcement Program." Accident Analysis and Prevention 38 (5): 862-70. 
North Central Texas Council of Governments. 2016. "Historical Traffic Counts." North Central Texas Council of Governments. https://trafficcounts.nctcog.org/trafficcount/ (accessed November 2016).

Oaklander, Mandy. 2011. “The Red-Light Camera Circus.” Houston Press, September 14. https:// www.houstonpress.com/news/the-red-light-camera-circus-6590999.

Olson, Bradley. 2010. "Houston Council OKs Putting Red Light Cameras on the Ballot." Houston Chronicle, August 24. https://www.chron.com/news/houston-texas/article/Houston-council-OKsputting-red-light-cameras-on-1716438.php.

-Parry, Ian W.H., and Kenneth A. Small. 2009. "Should Urban Transit Subsidies Be Reduced?" American Economic Review 99 (3): 700-724.

-Persaud, Bhagwant, and Craig Lyon. 2007. "Empirical Bayes Before-After Safety Studies: Lessons Learned from Two Decades of Experience and Future Directions." Accident Analysis and Prevention 39 (3): 546-55.

-Porter, Bryan E., Kristie L. Johnson, and Johnnie F. Bland. 2013. "Turning Off the Cameras: Red Light Running Characteristics and Rates after Photo Enforcement Legislation Expired." Accident Analysis and Prevention 50: 1104-11.

-Pulugurtha, Srinivas S., and Ramesh Otturu. 2014. "Effectiveness of Red Light Running Camera Enforcement Program in Reducing Crashes: Evaluation Using 'Before the Installation,' 'After the Installation,' and 'After the Termination' Data." Accident Analysis and Prevention 64: 9-17.

-Retting, Richard A., Susan A. Ferguson, and A. Shalom Hakkert. 2003. "Effects of Red Light Cameras on Violations and Crashes: A Review of the International Literature." Trafffic Injury Prevention 4 (1): 17-23.

- Retting, Richard A., and Sergey Y. Kyrychenko. 2002. "Reductions in Injury Crashes Associated With Red Light Camera Enforcement in Oxnard, California." American Journal of Public Health 92 (11): 1822-25.

Rosenbaum, Paul R., and Donald B. Rubin. 1983. "The Central Role of the Propensity Score in Observational Studies for Causal Effects." Biometrika 70 (1): 41-55.

-Shin, Kangwon, and Simon Washington. 2007. "The Impact of Red Light Cameras on Safety in Arizona." Accident Analysis and Prevention 39 (6): 1212-21.

Small, Kenneth A., and Erik T. Verhoef. 2007. The Economics of Urban Transportation. New York: Routledge.

Stein, Robert, Ned Levine, and Tim Lomax. 2006. "Criteria for Red Light Camera Intersection Selection."

Texas Department of Transportation (TxDOT). 2009-2016. "Crash Data Analysis Statistics.” Texas Department of Transportation. https://www.txdot.gov/inside-txdot/division/traffic/crash-statistics. html (accessed May 2017).

University of Texas at Austin Center for Transportation Research. 2003-2009. "Crash Records Information System.” CRIS Query. https://dataverse.harvard.edu/dataset.xhtml?persistentId=doi:10.7910/DVN/ GGLKEM (accessed December 2017).

US Department of Transportation Federal Highway Administration. 2009. "Manual on Uniform Traffic Control Devices for Streets and Highways." US Department of Transportation. https:// mutcd.fhwa.dot.gov/ (accessed July 2017).

-Waldo, Gordon P., and Theodore G. Chiricos. 1972. "Perceived Penal Sanction and Self-Reported Criminality: A Neglected Approach to Deterrence Research.” Social Problems 19 (4): 522-40.

-Wong, Timothy. 2014. "Lights, Camera, Legal Action! The Effectiveness of Red Light Cameras on Collisions in Los Angeles." Transportation Research Part A: Policy and Practice 69: 165-82.

- Yang, C.Y. David, and Wassim G. Najm. 2007. "Examining Driver Behavior Using Data Gathered from Red Light Photo Enforcement Cameras." Journal of Safety Research 38 (3): 311-21. 